\title{
Facile Green Approach for Developing Electrochemically Reduced Graphene Oxide-Embedded Platinum Nanoparticles for Ultrasensitive Detection of Nitric Oxide
}

\author{
Georgeena Mathew, Naresh Narayanan, Daniel Arulraj Abraham, Mrinmoy De, \\ and Bernaurdshaw Neppolian*
}

Cite This: ACS Omega 2021, 6, 8068-8080

Read Online

ABSTRACT: Nitric oxide (NO) plays a crucial and important role in cellular physiology and also acts as a signaling molecule for cancer in humans. However, conventional detection methods have their own limitations in the detection of $\mathrm{NO}$ at low concentrations because of its high reactivity and low lifetime. Herein, we report a strategy to fabricate $\mathrm{Pt}$ nanoparticle-decorated electrochemically reduced graphene oxide (erGO)-modified glassy carbon electrode (GCE) with efficiency to detect $\mathrm{NO}$ at a low concentration. For this study, Pt@erGO/GCE was fabricated by employing two different sequential methods [first GO reduction followed by $\mathrm{Pt}$ electrodeposition (SQ-I) and $\mathrm{Pt}$ electrodeposition followed by GO reduction (SQ-II)]. It was interesting to note that the electrocatalytic current response for SQ-I $(184 \mu \mathrm{A})$ was $\sim 15$ and $\sim 3$ folds higher than those of the bare GCE $(11.7 \mu \mathrm{A})$ and SQ-II $(61.5 \mu \mathrm{A})$. The higher current response was mainly attributed to a higher diffusion coefficient and electro-

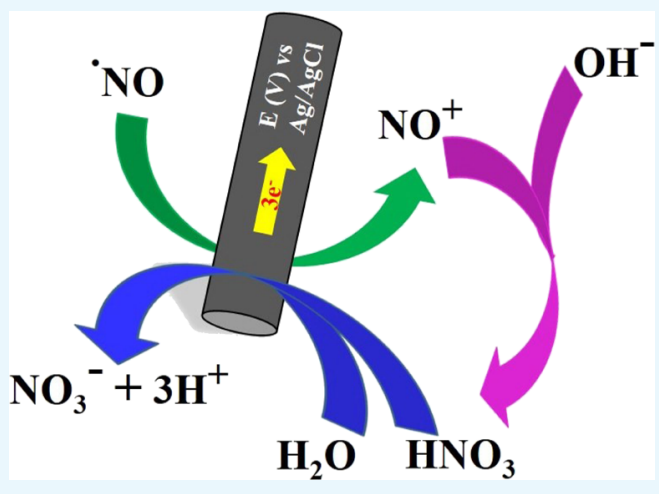
chemically active surface area. The proposed SQ-I electrode exhibited a considerably low LOD of $52 \mathrm{nM}(\mathrm{S} / \mathrm{N}=3)$ in a linear range of $0.25-40 \mu \mathrm{M}$ with a short response time ( $0.7 \mathrm{~s})$. In addition, the practical analytical applicability of the proposed sensor was also verified.

\section{INTRODUCTION}

Nitric oxide (NO) is a free radical cellular signaling molecule in the biological system, produced through the L-arginine NO synthase pathway or through alternative enzymatic and nonenzymatic nitrate-nitrite NO pathways. ${ }^{1-5}$ Besides, this NO also exhibits antimicrobial and antitumor properties. ${ }^{6,7}$ The rate of NO formation differs from species to species and in humans, it is found to be $\sim 1 \mu \mathrm{M}$ to $10 \mathrm{nM}$. $^{8}$ It is well known that NO plays a very crucial role in various physiological processes, such as vascular homeostasis, regulating blood pressure, energy balance, gene expression, immune response, neural communication, reproduction, and so forth. Furthermore, any disturbance in the concentration of NO can be related to various diseases namely, diabetes, thyroid disorders, metabolic syndrome, hypertension, heart failure, cardiovascular disease, obesity, arteriolosclerosis, and impotence. In addition, the excessive production of $\mathrm{NO}$ has also been reported during several neurological disorders namely, Alzheimer's disease, multiple sclerosis, amyotrophic lateral sclerosis, and Parkinson's disease. ${ }^{9-11}$

Hence, NO could be used as a potential and suitable biomarker for various diseases of the body. Therefore, the accurate quantification and detection of $\mathrm{NO}$ are of paramount importance to understand abnormalities present in the human body. However, NO being a free radical with large diffusivity, limited water solubility, low concentration, and a short lifetime as it is highly reactive with metal-containing proteins and other radicals in biological systems makes real-time direct detection of NO more challenging. In addition to these, one has to cross various hurdles in fabricating a selective and sensitive sensor for direct measurement of NO production, which is insensitive toward interferents along with a quick response time. Hence, the electrochemical method is considered as the most convenient method for the sensing of $\mathrm{NO}$ in comparison with other conventional methods. ${ }^{12,13}$ However, the electrochemical signals produced by conventional electrodes are too weak because of the sluggish electron transfer rate and the fouling effect caused by the biomaterials, which lead to inefficient electrochemical sensing. ${ }^{14}$ These demerits of conventional electrodes hinder the accurate detection of biomolecules at low concentrations with high sensitivity and selectivity. In order to overcome these limitations, conven-

Received: November 19, 2020

Accepted: February 12, 2021

Published: March 18, 2021

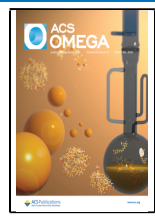



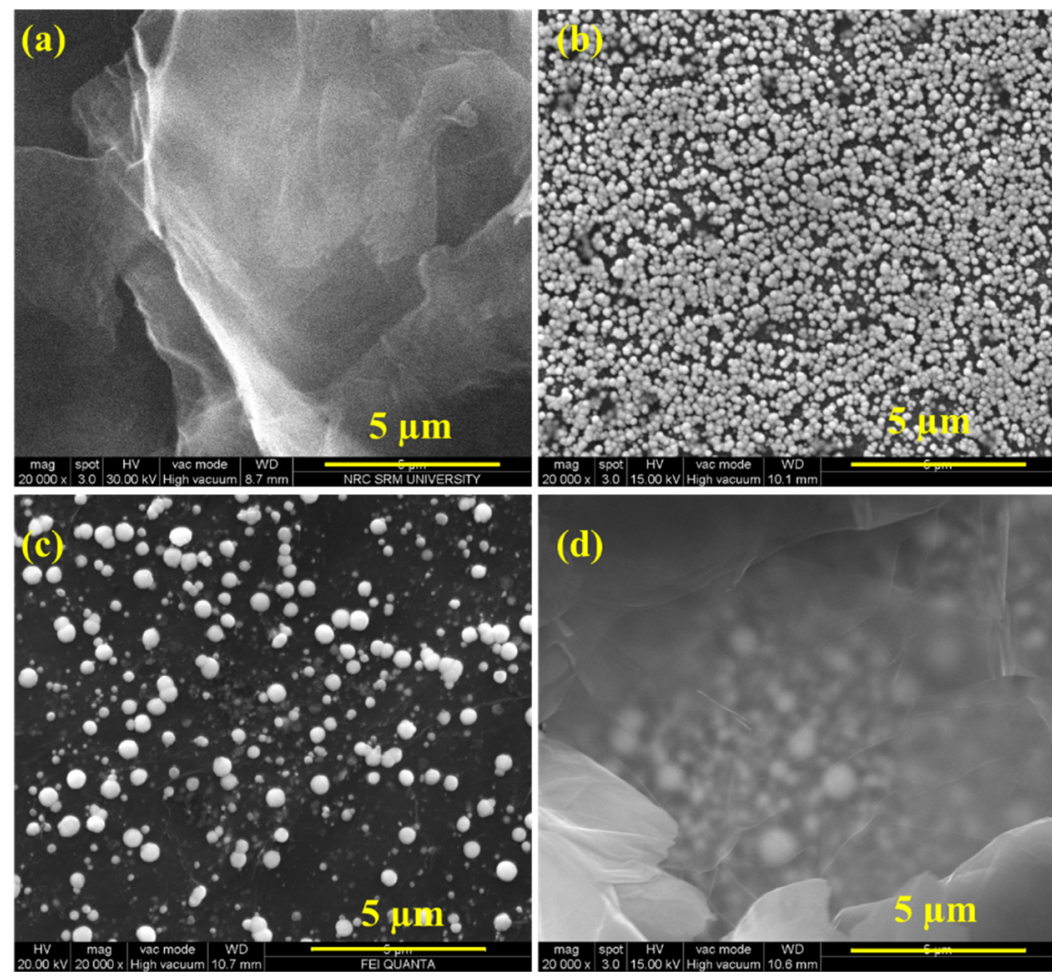

(d)

Figure 1. FESEM images obtained for (a) erGO, (b) Pt, (c) Pt-erGO (SQ-I), and (d) erGO-Pt (SQ-II).

tional electrodes, such as a glassy carbon electrode surface could be modified by introducing various potential nanomaterials. $^{15-24}$

In recent years, various modified electrodes have been designed and fabricated for electrochemical detection of NO. ${ }^{25-39}$ Lately, graphene-supported nanomaterials have been emerged as promising electrocatalysts for various applications including sensors. ${ }^{40-45}$ Graphene is a $2 \mathrm{D}$ carbon sheet having a single-atom thickness, a high conductivity at room temperature $\left(10^{6} \mathrm{~S} \mathrm{~cm}^{-1}\right)$, and a large theoretical surface area $\left(2630 \mathrm{~m}^{2} \mathrm{~g}^{-1}\right)$, and can be utilized in a wide electrochemical window. Additionally, graphene sheets can be used as excellent host materials for growing nanomaterials. ${ }^{28}$ Inorganic graphene analogues, such as modified or $(\mathrm{Pt}, \mathrm{Au}$, and $\mathrm{Pd}$ ) nanoparticle (NP)-integrated graphene sheets help in achieving high carrier mobility and enhancement in the active surface area. ${ }^{46-49}$ Among the metal NPs, platinum (Pt) NPs have been paid special attention because of their morphologydependent electrocatalytic activities, optical properties, fast electron transfer in the electrode surface, and biocompatibility. Most importantly, the shape and size of the Pt NPs can be easily controlled during the synthesis. Thus, Pt NPs are employed for electrode modification because of their good biocompatibility as well as high surface to volume ratio. ${ }^{50,51}$ Consequently, anchoring $\mathrm{Pt} \mathrm{NPs}$ to the derivatives of graphene, like graphene oxide $(\mathrm{GO})$ and reduced graphene oxide ( $\mathrm{rGO}$ ), is attractive, and to this end, various methods, such as hydrothermal, ultrasound-assisted, in situ chemical reduction, and so forth, have been demonstrated. ${ }^{52-55}$ However, the lack of control over uniform dimensions, anchoring strength and dispersion of the Pt NPs onto rGO, and so forth, often limits their applications. Consequently, the electrochemical method stands out to be more advantageous in terms of its environmentally friendly, cost-effective, and fast and green approach. Additionally, the residual unreduced oxygen functional groups present in erGO can promote faster electron transfer and aid in nucleation and growth of Pt NPs uniformly. Thus, the electrochemically formed Pt NPs on the erGO surface can lead to an increase in the effective surface area and hinder agglomeration of Pt NPs. ${ }^{56}$ Moreover, the electrochemical method utilizes electrons as the reductants, which minimize the presence of impurities in the final product than the other methods. ${ }^{57-60}$ Hence, electrochemical synthesis of nanocomposites has attracted huge interest of researchers worldwide.

In this work, we have fabricated a Pt@erGO-modified GCE via a simple green synthesis method using a sequential electrochemical process to study the influence of the fabrication route on sensing of NO. It is quite interesting to learn that the effect of fabrication routes on the NO detection has not been studied to date and these sequential methods have been thoughtfully exploited. The sequential deposition of Pt and erGO to GCE (SQ-I and SQ-II) is enticing as the synergistic effect of coordinate property exerted by $\mathrm{Pt}$ on $\mathrm{NO}$ and rapid electron transport facilitated by the erGO support resulted in ultrasensitive $\mathrm{NO}$ detection. The fabrication routes greatly resulted in a difference in the sensitivity, accuracy, selectivity, and stability.

\section{RESULTS AND DISCUSSION}

2.1. Characterization of Composites. The field-emission scanning electron microscopy (FESEM) images, X-ray diffraction (XRD) patterns, Fourier transform infrared (FTIR) spectra, and Raman spectra were used to demonstrate the successful synthesis of both Pt-erGO and erGO-Pt. The morphological structures of GO, erGO, Pt NPs, Pt-erGO, and erGO-Pt were determined using FESEM images (Figures 1 and S1). The prepared GO exhibits a multiple layered structure (Figure S1). After the electrochemical reduction of $\mathrm{GO}$ to erGO, it appears as a crinkled paper-like structure that 

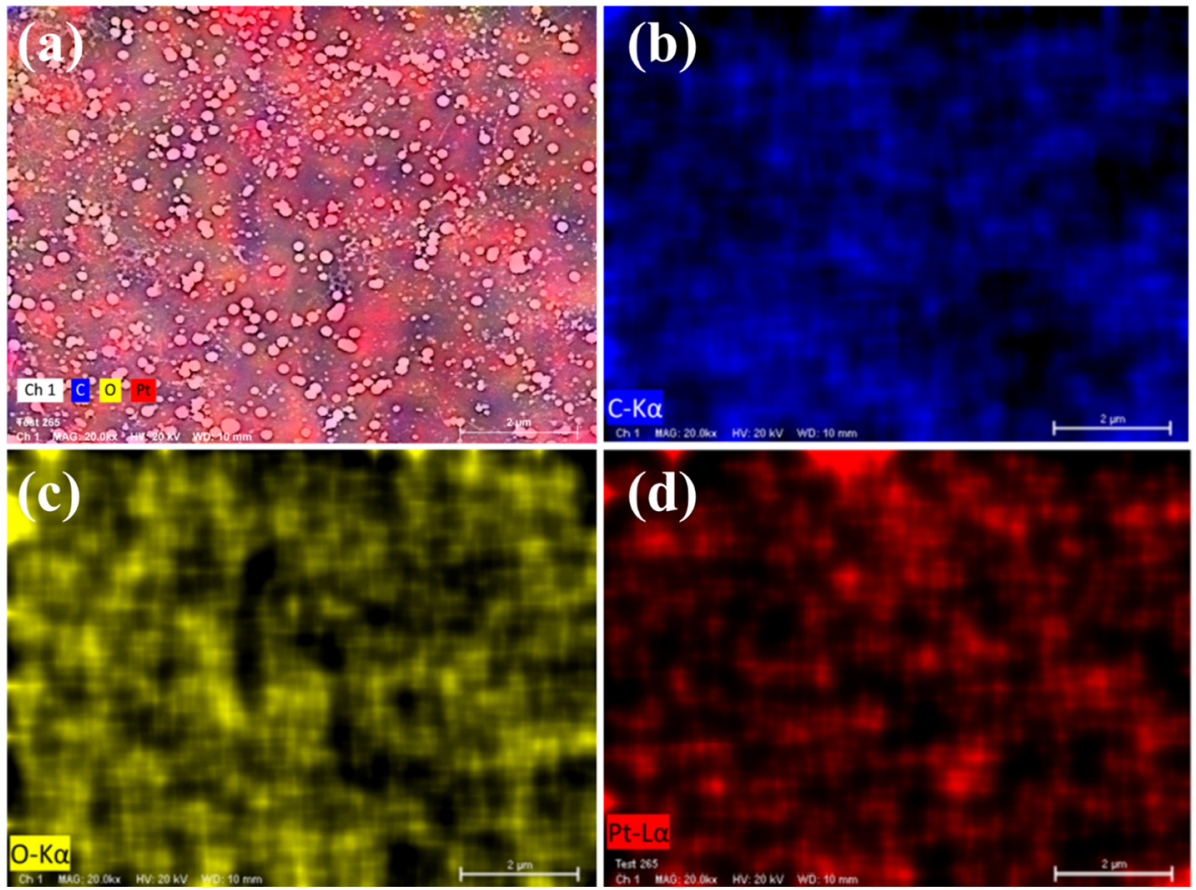

Figure 2. (a) Elemental mapping of Pt-erGO (SQ-I), (b) carbon, (c) oxygen, and (d) platinum.

(a)

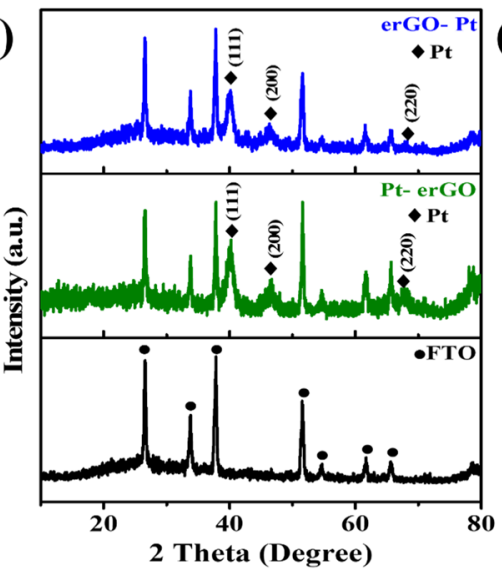

(b)

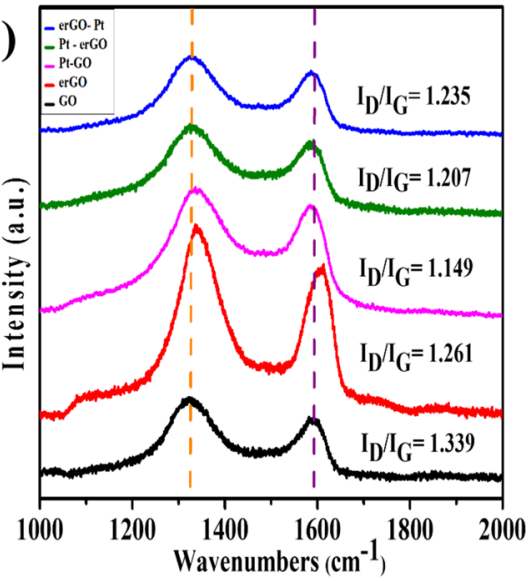

Figure 3. (a) XRD patterns obtained for FTO, Pt-erGO, and erGO-Pt and (b) Raman spectra obtained for GO, erGO, Pt-GO, Pt-erGO, and erGO-Pt.

indicates the lattice defects in erGO as shown in Figure 1a. ${ }^{61}$ Figure $1 b-d$ shows the FESEM images obtained for Pt NPs, $\mathrm{Pt}-\mathrm{erGO}$, and erGO-Pt. The electrodeposited Pt NPs appear to have a sphere like morphology with an average particle size of $547 \pm 36 \mathrm{~nm}$ (Figure 1b). Additionally, it was observed that the electrodeposited Pt NPs were heavily agglomerated. Figure 1c,d represents the formation of Pt@erGO composites via SQI and SQ-II techniques. It can be clearly seen from Figure 1c that the Pt NPs are anchored against the erGO surface uniformly in the $\mathrm{Pt}-\mathrm{erGO}$ composite prepared via SQ-I. The partially reduced functional groups present in erGO act as nucleation and anchoring sites for the Pt NPs to grow uniformly on the erGO surface. Furthermore, erGO sheets prevent the agglomeration of Pt NPs as seen clearly in Figure 1c. Hence, it was noted that the growth of Pt NPs on erGO was less agglomerated with a uniform distribution than on the bare surface. In the case of SQ-II, the initially electrodeposited agglomerated Pt NPs were wrapped completely by the erGO sheets (Figure 1d). Consequently, the active sites of Pt NPs were masked by the erGO sheets that may lead to poor NO detection. The elemental mapping and energy-dispersive X-ray spectra (EDS) of SQ-I are illustrated in Figures 2 and S2. It is seen from Figures 2 and S2 that the fabricated SQ-I is composed of $\mathrm{C}, \mathrm{O}$, and $\mathrm{Pt}$.

The XRD patterns of the GO, erGO, Pt-erGO, and erGOPt samples on FTO glass were recorded (Figures $3 a$ and S3). The XRD pattern of GO displayed a distinguishable peak at $2 \theta$ $=10.7^{\circ}$ indexing the (002) plane corresponding to the oxygencontaining functional groups present between the GO layers. Besides, a broad peak is also observed in the range of $2 \theta=17-$ $24^{\circ}$ representing the parallel stacking of the GO sheets. In contrast to XRD profile of erGO, no peak was observed at the (002) plane, which implies the reduction of GO to erGO during the electrochemical treatment. A broad peak in the range of $2 \theta=17-24^{\circ}$ appearing in the case of erGO indicates parallel stacking of erGO sheets with a less interlayer spacing 

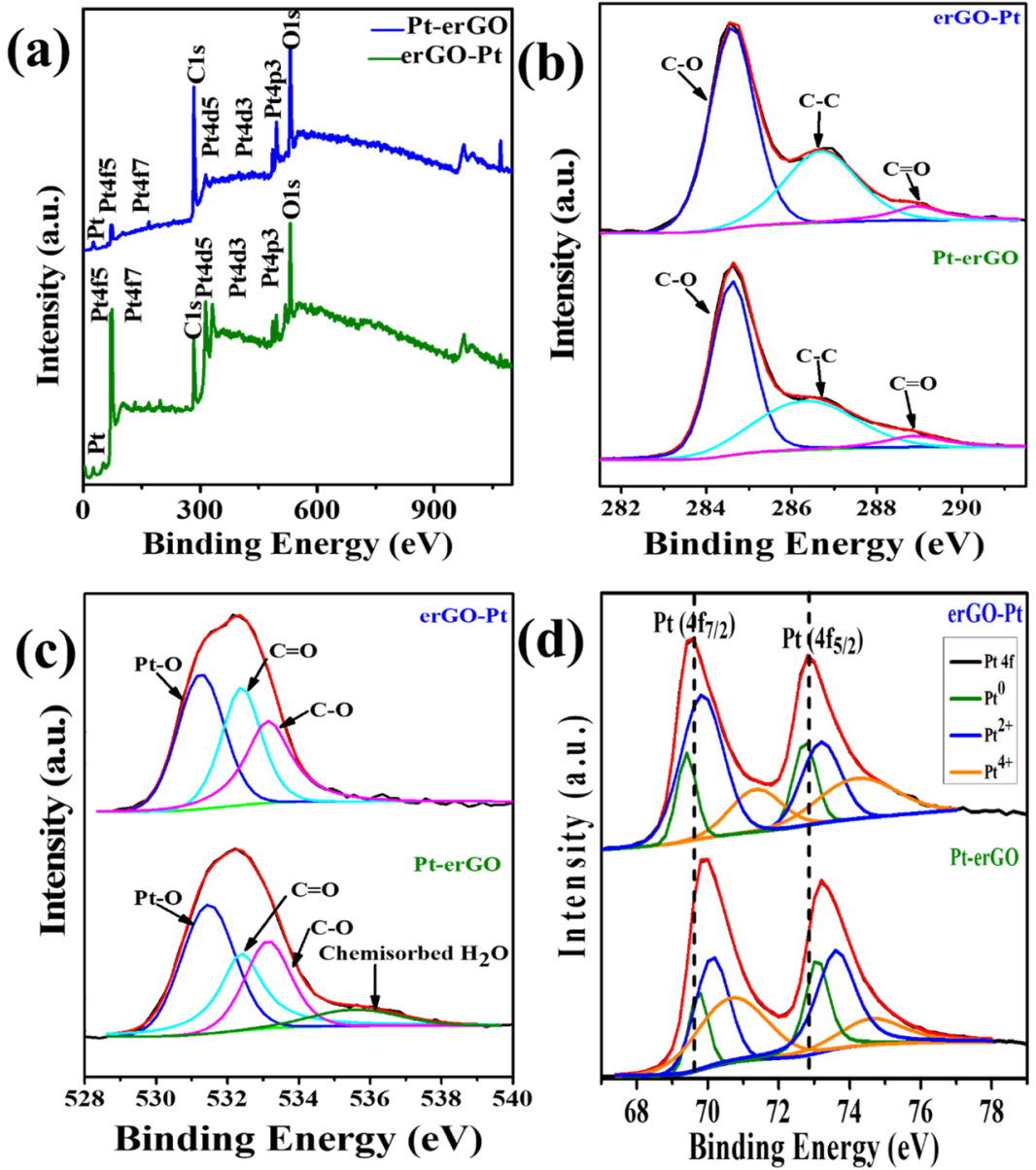

Figure 4. (a) XPS survey spectra of Pt-erGO and erGO-Pt, (b) deconvoluted spectra of $\mathrm{C} 1 \mathrm{~s}$, (c) deconvoluted spectra of O 1s, and (d) deconvoluted spectra of $\mathrm{Pt} 4 \mathrm{f}$.

(Figure S3). ${ }^{62}$ However, from Figure $3 \mathrm{a}$, erGO-Pt and $\mathrm{Pt}-$ erGO show a broad intense peak in the range of $2 \theta=17-24^{\circ}$ overlapped by the peak of $\mathrm{SiO}_{2}$ (FTO-glass). ${ }^{62}$ Furthermore, peaks at $2 \theta=40.04^{\circ}, 46.26^{\circ}$, and $68.02^{\circ}$ of $\mathrm{Pt}(111), \mathrm{Pt}(200)$, and $\mathrm{Pt}$ (220) planes arise from face-centered cubic (fcc) Pt. ${ }^{63,64}$ The XRD patterns obtained for FTO glass are in accordance with the previous literature. ${ }^{65}$ It confirms the successful fabrication of the both sequential electrodes.

FTIR analyses of GO, erGO, Pt-erGO, and erGO-Pt nanomaterials were carried out to study the functional groups present in each sample (Figure S4). In the case of GO, distinct peaks appear at $3199.5,1719.6,1622.0,1382.9,1232.4$, and $1047.0 \mathrm{~cm}^{-1}$ attributed to the $-\mathrm{OH}$ stretching vibrations, carboxylic acid group vibrations, residual $\mathrm{sp}^{2}$ hybridized $\mathrm{C}$ groups, tertiary $\mathrm{C}-\mathrm{OH}$ groups, deformation of the symmetric epoxy ring, and $\mathrm{C}-\mathrm{O}$ stretching vibrations of alkoxy groups, respectively, as shown in Figure S4. After electrochemical reduction treatment, for erGO, $\mathrm{Pt}-\mathrm{erGO}$, and erGO-Pt, the peak intensities of all functional groups except for the residual $\mathrm{sp}^{2}$ hybridized $\mathrm{C}$ groups $\left(1622.0 \mathrm{~cm}^{-1}\right)$ were reduced. Hence, the FTIR spectra confirm the reduction of $\mathrm{GO}$ in erGO, PterGO, and erGO-Pt. ${ }^{66}$

Furthermore, the successful formation of the Pt-erGO and erGO nanocomposites was also determined using FT-Raman analysis. The Raman spectra of GO, erGO, Pt-GO, erGO-Pt, and $\mathrm{Pt}$-erGO samples on the FTO substrate obtained at 633 $\mathrm{nm}$ excitation are shown in Figure $3 \mathrm{~b}$. As seen in Figure $3 \mathrm{~b}$, both Pt-erGO and erGO-Pt exhibit strong D (defect) and G (graphite) bands, which are centered at 1327 and $1686 \mathrm{~cm}^{-1}$, respectively. ${ }^{67,68}$ The intensity ratios of the $\mathrm{D} / \mathrm{G}$ peaks reflect the quality of the reduction process of $\mathrm{GO}$ to erGO and interaction of Pt NPs with GO during the formation of PterGO and erGO-Pt nanocomposites. From the results obtained, the calculated $I_{\mathrm{D}} / I_{\mathrm{G}}$ ratio for $\mathrm{GO}$ is 1.339 , which is relatively higher than those of $\mathrm{Pt}-\mathrm{erGO}(1.207)$ and erGO-Pt (1.235). This result can be taken into account to explain the interaction between the $\mathrm{Pt}$ NPs and GO through their defective sites during the electrochemical reduction of GO. This is responsible for the reduction of peak intensity of the $\mathrm{D}$ band. Thus, a low $I_{\mathrm{D}} / I_{\mathrm{G}}$ ratio for $\mathrm{Pt}-\mathrm{erGO}$ is noted in comparison to that of erGO. Furthermore, a nominal blue shift is witnessed for $\mathrm{D}$ and $\mathrm{G}$ bands of the $\mathrm{Pt}-\mathrm{erGO}$ and erGO-Pt composites with respect to $\mathrm{Pt}-\mathrm{GO}$, indicating the incorporation of $\mathrm{Pt}$ NPs on the erGO surface and also the electrochemical reduction of oxygen functional groups of GO to form erGO. ${ }^{22}$

To explore the chemical constitution and valence state of the surface elements present in SQ-I and SQ-II, the X-ray photoelectron spectroscopic (XPS) analysis was employed and the results obtained are shown in Figure $4 a-d$. The survey scan spectrum of both SQ-I and SQ-II shows the presence of the $\mathrm{C}, \mathrm{O}$, and Pt elements as revealed in Figure 4a. All the respective spectral analogues of $\mathrm{C} 1 \mathrm{~s}, \mathrm{O} 1 \mathrm{~s}$, and $\mathrm{Pt} 4 \mathrm{f}$ were deconvoluted and fitted by using the Gaussian function. As shown in Figure $4 \mathrm{~b}$, the $\mathrm{C} 1 \mathrm{~s}$ spectra were deconvoluted into three different peaks at 284.6, 286.71, and $288.96 \mathrm{eV}$ 

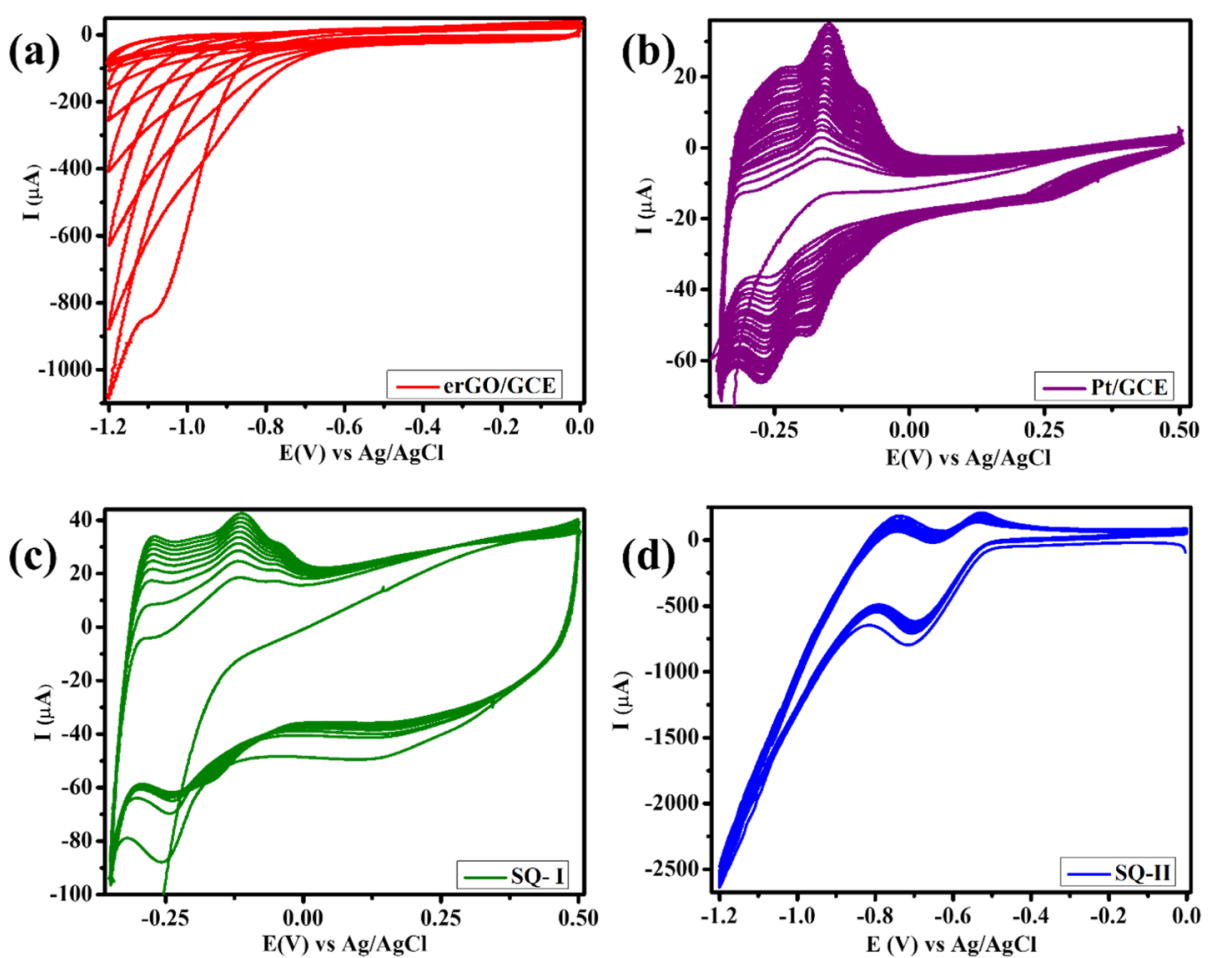

Figure 5. CVs obtained for fabrication of (a) erGO/GCE, (b) Pt/GCE, (c) SQ-I, and (d) SQ-II electrodes.

(a)

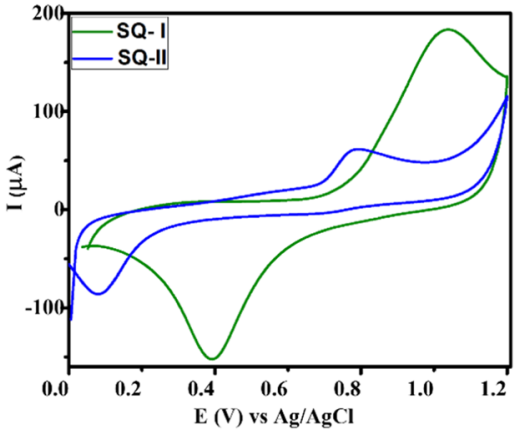

(c)

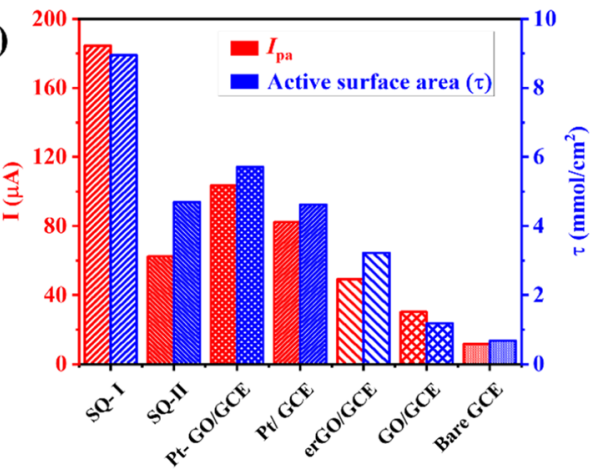

(b)

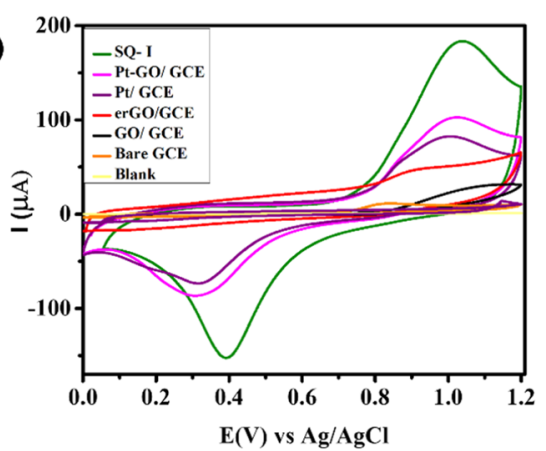

(d)

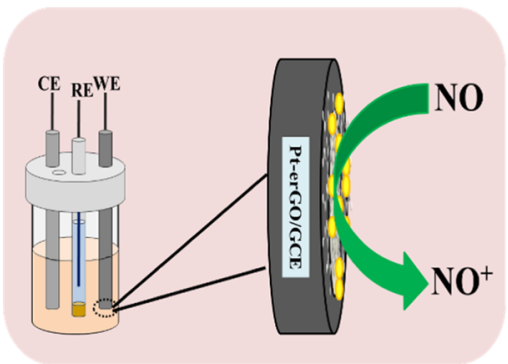

Figure 6. (a) CVs obtained for detection of $\mathrm{NO}$ at SQ-I and SQ-II electrode surfaces in $0.1 \mathrm{M} \mathrm{PBS}$ (pH 2.5) containing $0.5 \mathrm{mM}$ NO, (b) CVs obtained for the detection of $\mathrm{NO}$ at Bare/GCE, GO/GCE, erGO/GCE, Pt/GCE, Pt-GO/GCE, and Pt-erGO/GCE surfaces in 0.1 M PBS (pH 2.5) containing $0.5 \mathrm{mM} \mathrm{NO}$, (c) bar diagram representing the obtained $I_{\mathrm{pa}}$ (red) and active surface area $(\tau)$ (blue) for bare and modified electrodes. (d) Schematic presentation of NO detection at Pt-erGO/GCE.

corresponding to the $\mathrm{C}-\mathrm{C}, \mathrm{C}-\mathrm{O}$, and $\mathrm{C}=\mathrm{O}$ bonds of $\mathrm{rGO}$ present in SQ-I and SQ-II, respectively. ${ }^{69,70}$ Furthermore, the $\mathrm{O}$ 1s spectrum (Figure 4c) was deconvoluted with several peaks at $531.48,532.39$, and $533.15 \mathrm{eV}$ corresponding to $\mathrm{Pt}-$ $\mathrm{O}, \mathrm{C}=\mathrm{O}$, and $\mathrm{C}-\mathrm{O}$ for both SQ-I and SQ-II. ${ }^{69,70}$ Additionally, the SQ-II peak at $535.58 \mathrm{eV}$ was noted and assigned to chemisorbed water molecules, which limit the NO detection efficiency for SQ-II compared to SQ-I. More importantly, the Pt $4 \mathrm{f}$ high-resolution spectra (Figure 4d) were deconvoluted into three different chemical states of Pt. As a result, two prime peaks at $69.7 \mathrm{eV}\left(\mathrm{Pt}_{4} \mathrm{f}_{7 / 2}\right)$ and $73 \mathrm{eV}\left(\mathrm{Pt}_{4 / 2}\right)$ in SQ-I, which are attributed to the $\mathrm{Pt}^{0}$ oxidation state in SQ-I. Also, peaks at 
binding energy $(\mathrm{BE})$ values of 70.1 and $73.6 \mathrm{eV}$ are ascribed to the spin orbit coupling pair of $\mathrm{Pt} 4 \mathrm{f}_{7 / 2}$ and $\mathrm{Pt} 4 \mathrm{f}_{5 / 2}$ of the $\mathrm{Pt}^{+2}$ state present in SQ-I, respectively. Additionally, the peaks at 70.7 and $74.6 \mathrm{eV}$ are attributed to the pair of $\mathrm{Pt} 4 \mathrm{f}_{7 / 2}$ and $\mathrm{Pt}$ $4 \mathrm{f}_{5 / 2}$ confirming the presence of the $\mathrm{Pt}^{+4}$ oxidation state in SQI as demonstrated in Figure 4 d. $^{70,71}$ Similarly, in the case of SQ-II, a positive shift was observed in the BE value because of the reduction in electron density of metallic Pt.

2.2. Electrochemical Studies. 2.2.1. Electrochemical Fabrication of Modified Electrodes. The continuous cyclic voltammograms (CVs) were recorded for the fabrication of erGO/GCE, Pt/GCE, SQ-I, and SQ-II electrodes (given in Figure 5). The successive $15 \mathrm{CVs}$ of the GO-modified GCE to form erGO/GCE were carried out in 0.1 M PBS. A significant cathodic peak current is observed at $-1.02 \mathrm{~V}$ with respect to $\mathrm{Ag} / \mathrm{AgCl}$ in Figure 5a, which corresponds to the reduction of oxygen functional groups such as hydroxyl, epoxide, and carboxyl groups near the basal plane of graphene. The cathodic peak obtained in the first cycle of scanning is found to decrease considerably with increasing scanning cycles and vanish almost completely after several scanning cycles, confirming the rapid and irreversible electrochemical reduction of GO.

The electrodeposition of Pt NPs on GCE was achieved via 20 successive CVs. As shown in Figure 5b, a peak at $-0.16 \mathrm{~V}$ appears in the forward scan, representing the reduction of $\mathrm{Pt}(\mathrm{IV})$ to $\mathrm{Pt}(\mathrm{II})$. On the other hand, the second peak formed near $-0.08 \mathrm{~V}$ denotes the reduction of $\mathrm{Pt}(\mathrm{IV})$ and/or $\mathrm{Pt}(\mathrm{II})$ to $\mathrm{Pt}(0)$, respectively. The overall reaction involved in the electrodeposition of Pt NPs from hydrogen hexachloroplatinate solution (equ 1) is as follows ${ }^{20}$

$$
\mathrm{PtCl}_{6}{ }^{2-}+4 \mathrm{e}^{-} \rightarrow \mathrm{Pt}+6 \mathrm{Cl}^{-}
$$

Finally, the electrochemical fabrication of SQ-I and SQ-II electrodes is shown in Figure 5c,d. The peaks corresponding to Pt NPs and GO reduction appear for the two fabrication techniques as shown in Figure $5 \mathrm{c}$,d.

2.2.2. Electrocatalytic Oxidation of $N O$ at Bare and Modified Electrodes. The effect of fabrication methods that were adopted for developing SQ-I and SQ-II on electrochemical detection of $\mathrm{NO}$ was evaluated by cyclic voltammetry in $0.1 \mathrm{M}$ PBS of $\mathrm{pH} 2.5$ containing $\mathrm{NaNO}_{2}$ as the precursor for $\mathrm{NO}$ (Figure 6a). $\mathrm{NaNO}_{2}$ produces $\mathrm{NO}$ under acidic conditions by the disproportionation reaction as given below (eqs 2 and 3). ${ }^{29}$

$$
\begin{aligned}
& \mathrm{NaNO}_{2}+\mathrm{H}^{+} \rightarrow \mathrm{HNO}_{2}+\mathrm{Na}^{+} \\
& 3 \mathrm{HONO} \rightarrow \mathrm{H}^{+}+2 \mathrm{NO}+\mathrm{NO}_{3}{ }^{-}+\mathrm{H}_{2} \mathrm{O}
\end{aligned}
$$

It is seen in Figure 6a that the $\mathrm{CV}$ obtained for two electrodes exhibits a distinguishable anodic cathodic peak. The usual reaction takes place between the electrode surface and the electrolyte, when potential is applied as provided in eqs 4-6. The anodic peak current in the forward scan indicates the electrochemical oxidation of $\mathrm{NO}$ to the nitrosonium $\left(\mathrm{NO}^{+}\right)$ ion via an electron transfer from NO (eq 4). ${ }^{56,72}$

$$
\begin{aligned}
& \mathrm{NO} \rightarrow \mathrm{NO}^{+}+\mathrm{e}^{-} \\
& \mathrm{NO}^{+}+\mathrm{OH}^{-} \rightarrow \mathrm{HNO}_{2} \\
& \mathrm{HNO}_{2}+\mathrm{H}_{2} \mathrm{O} \rightarrow \mathrm{NO}_{3}^{-}+2 \mathrm{e}^{-}+3 \mathrm{H}^{+}
\end{aligned}
$$

The anodic $\left(I_{\mathrm{pa}}\right)$ peak current, corresponding to the peak potential $\left(E_{\mathrm{pa}}\right)$ and current densities of the voltammogram obtained from SQ-I and SQ-II electrodes, is given in the Supporting Information Table S1. It is clear (Table S1) that SQ-I has shown enhanced electrocatalytic activity $\left(I_{\mathrm{pa}} \sim 184\right.$ $\mu \mathrm{A})$ toward the oxidation of $\mathrm{NO}$ in comparison with the SQ-II electrode with a higher $E_{\mathrm{pa}}$ value for SQ-I $(1.03 \mathrm{~V})$ than the SQ-II $(0.78 \mathrm{~V})$ electrode. Similarly, the current response exhibited by the SQ-I electrode fabricated via SQ-I is found to be $\sim 3$ fold more than that of the current response exhibited by the SQ-II $(61.5 \mu \mathrm{A})$ electrode. Additionally, it is evident from Table S1 that SQ-I $\left(23,507.00 \mu \mathrm{A} / \mathrm{cm}^{2}\right)$ exhibited a high current response as well as current density in comparison to SQ-II $\left(7945.22 \mu \mathrm{A} / \mathrm{cm}^{2}\right)$.

To further support, electron transfer kinetics of both the electrodes and bare GCE were evaluated using electrochemical impedance spectroscopy (EIS). The Nyquist plots obtained for SQ-I, SQ-II, and bare electrodes are depicted in Figure S5 (Supporting Information). It is clear from Figure S5 that SQ-I exhibits a lower charge transfer resistance in comparison to bare GCE and SQ-II electrodes. This confirms the electron transfer rate at the SQ-I electrode surface is faster than that at SQ-II because of the low charge transfer resistance. Hence, low charge transfer resistance of SQ-I facilitates the efficient electrocatalytic oxidation of NO.

Furthermore, the enhanced electrochemically active surface areas (ECSAs) available at SQ-I and SQ-II electrodes were calculated using following eq 7

$$
\tau=\frac{Q}{n F A}
$$

where $Q$ is the integrated charge (C), $n$ is the electrons transferred, $F$ represents the Faradaic constant $(96,485.3 \mathrm{C}$ $\left.\mathrm{mol}^{-1}\right)$, and $A$ is the surface area of the electrode $\left(0.0707 \mathrm{~cm}^{2}\right)$. The $\tau$ values calculated for SQ-I and SQ-II are 8.95 and 4.69 $\mathrm{mmol} / \mathrm{cm}^{2}$, respectively (Figure $6 \mathrm{c}$, Table $\mathrm{S} 1$ ). Henceforth, it is clear that SQ-I possesses $\sim 2$ fold higher ECSA than SQ-II. This could aid in enhancing the electrochemical performance of SQ-I. Besides, the enhanced current response of SQ-I can be attributed to the excellent electrochemical catalytic properties achieved via SQ-I. SQ-I promotes easy anchoring of Pt NPs to the electrode surface modified with the erGO matrix, which acts as nucleation sites for the NP growth. ${ }^{73}$ Thus, SQ-I promotes the coordination of Pt NPs with NO and efficient electron transfer, which enhances the better sensitivity toward NO. In the case of SQ-II, the electrode surface is modified with Pt NPs prior to dropcasting and electroreduction of GO, which may lead to masking of Pt NPs by erGO. This results in poor coordination between the electrode surface and NO. As a result, the SQ-I electrode exhibits a higher current response for electrochemical oxidation of NO in comparison with the SQ-II electrode.

From the above studies, the SQ-I electrode is considered to be more apt for electrochemical detection of NO. Therefore, in order to increase the sensitivity and selectivity towards NO, GCE was further modified with $\mathrm{Pt}-\mathrm{erGO}$ via sequential method-I. The electrocatalytic oxidation of nitric oxide was carried out with bare, GO/GCE, erGO/GCE, Pt/GCE, Pt$\mathrm{GO} / \mathrm{GCE}$, and $\mathrm{Pt}-\mathrm{erGO} / \mathrm{GCE}$ electrodes in the presence of $0.5 \mathrm{mM} \mathrm{NO}$ in phosphate buffer solution ( $\mathrm{pH} 2.5$ ) (Figure $6 \mathrm{~b})$. The anodic $\left(I_{\mathrm{pa}}\right)$ current with the corresponding peak potential $\left(E_{\mathrm{pa}}\right)$, current densities, and active surface area $(\tau)$ obtained for bare and modified electrodes are given in the Supporting Information (Table S1). The oxidation potential for $\mathrm{NO}$ at the bare GCE surface was observed at $0.8334 \mathrm{~V}$ with 

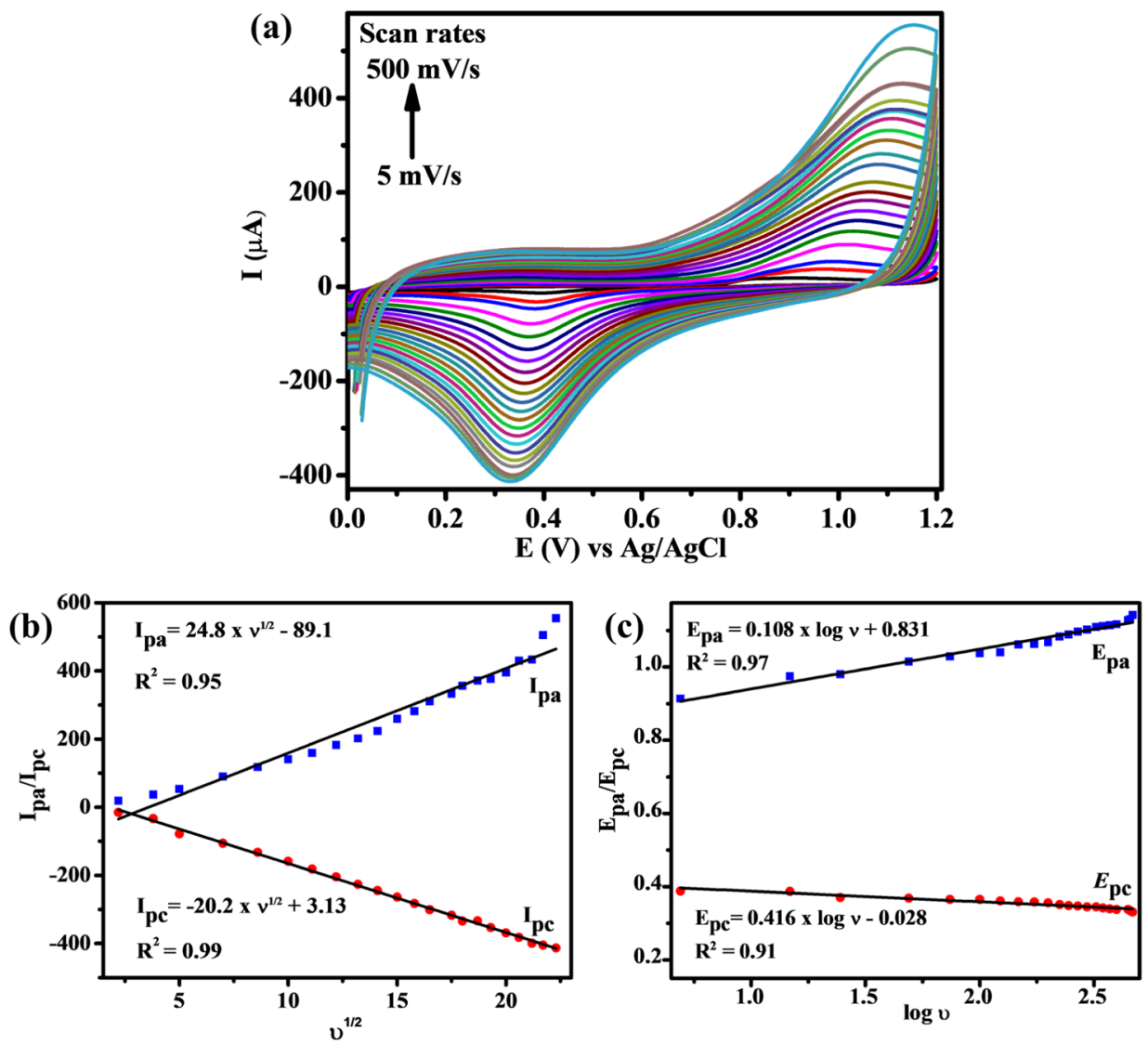

Figure 7. (a) Effect of different scan rates ( 5 to $500 \mathrm{mV} / \mathrm{s}$ ), (b) corresponding calibration plot of $I_{\mathrm{pa}} \mathrm{vs} \nu^{1 / 2}$, and (c) corresponding calibration plot of $E_{\mathrm{pa}}$ vs $\log \nu$

a low current response of $11.7 \mu \mathrm{A}$, indicating the incompetence of bare GCE in detecting NO (Figure 6b). Furthermore, modification of the GCE surface with GO, erGO, Pt NPs, and $\mathrm{Pt}-\mathrm{GO}$ gradually increased the anodic peak current in the order of $31,46,83$, and $102.9 \mu \mathrm{A}$ in accordance with the increased electrochemically active sites on the modified electrode (Figure 6c). Also it is worthy of note that a remarkable performance in terms of the electrochemical oxidation current response $(184 \mu \mathrm{A})$ and current density $\left(23,507.00 \mu \mathrm{A} / \mathrm{cm}^{2}\right)$ was obtained for SQ-I (Pt-erGO/GCE) in comparison to the individual counterparts in the current response of $\mathrm{Pt} / \mathrm{GCE}, \mathrm{GO} / \mathrm{GCE}$, erGO/GCE, and $\mathrm{Pt}-\mathrm{GO} /$ GCE. This enhancement in the current response and current density is because of the synergistic effect of $\mathrm{Pt}$ and erGO during the electrocatalytic oxidation of NO. The efficient and rapid electron transfer between the electrolyte and the modified electrode is facilitated by erGO and Pt NPs, which contributes to the enhanced current response during NO detection. Moreover, because of the high coordination nature of Pt NPs on the electrode Pt-erGO/GCE surface, they can interact with $\mathrm{NO}$ facilitating electron transfer between $\mathrm{NO}$ and fabricated sensor during an electrochemical catalytic reaction. In addition to this, SQ-I electrode exhibited 13.1 fold higher ECSA in comparison with bare GCE. This further results in $\sim 15$ fold enhancement in the electrocatalytic oxidation current response obtained for $\mathrm{NO}$ at the SQ-I surface with reference to the bare GCE. Hence, the enhanced sensitivity of Pt-erGO/ GCE toward NO compared to other modified electrodes and bare GCE was evaluated. Furthermore, experimental optimization was carried out using Pt-erGO/GCE (SQ-I). In light of the electrochemical studies carried out, a plausible mechanism for the electrochemical oxidation of $\mathrm{NO}$ at the SQ-I electrode is depicted in Figure 6d.

2.2.3. Influence of Scan Rate on the Electrochemical Oxidation of NO at SQ-I. Figure 7a depicts the influence of scan rate on the electrocatalytic detection of $\mathrm{NO}$ at the $\mathrm{Pt}-$ erGO/GCE surface and was evaluated using the cyclic voltammetric technique at different scan rates ranging from 5 to $500 \mathrm{mVs}^{-1}$ in the presence of $0.5 \mathrm{mM} \mathrm{NO}$ in PBS ( $\mathrm{pH} 2.5$ ). It is clearly seen from Figure $7 \mathrm{~b}$ that the anodic current and the scan rate have a linear relation and thus the electron transfer process in the electrochemical redox reaction of $\mathrm{NO}$ at $\mathrm{Pt}-$ erGO/GCE is a diffusion-controlled process rather than a surface-controlled process as there is a simultaneous increase in the anodic peak current $\left(I_{\mathrm{pa}}\right)$ and the square root of scan rate $\left(\nu^{1 / 2}\right) .^{74}$ The plot of peak currents $(I)$ versus $\nu^{1 / 2}$ can be expressed as the following linear regression eq 8

$$
I_{\mathrm{pa}}=24.8 \times v^{1 / 2}-89.1, R^{2}=0.95
$$

(for NO oxidation)

From the above results, the diffusion coefficients $\left(D_{\text {app }}\right)$ for bare GCE, SQ-I, and SQ-II were calculated using RandlesSevcik's eq $9^{29}$

$$
I_{\mathrm{pa}}=0.4463 n F A C\left[\left(n F v D_{\mathrm{app}}\right) /(R T)\right]^{1 / 2}
$$

here, $I_{\mathrm{pa}}$ is the anodic peak current (A), $C$ denotes the concentration of $\mathrm{NO}$ in mol cm${ }^{-3}, \nu$ is the scan rate $\left(\mathrm{V} \mathrm{s}^{-1}\right), R$ and $T$ are the universal gas constant $\left(8.314 \mathrm{~J} \mathrm{~K}^{-1} \mathrm{~mol}^{-1}\right)$ and temperature in $\mathrm{K}$, and $D_{\text {app }}$ is the diffusion coefficient of 
(a)

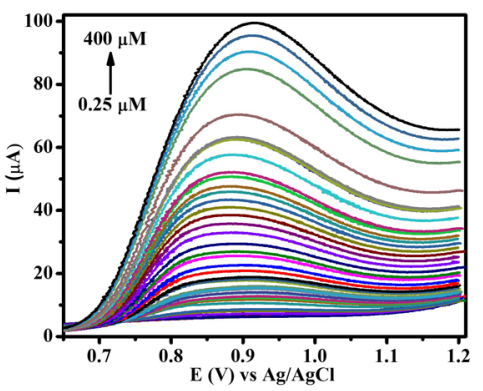

(c)

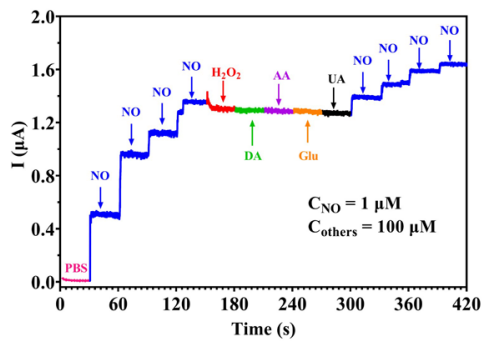

(e)

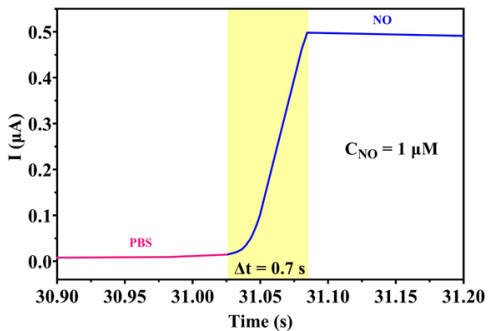

(b)

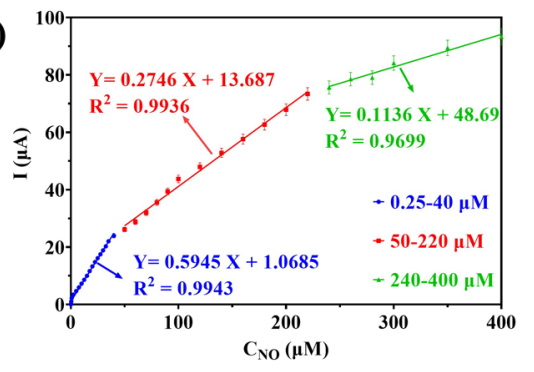

(d)

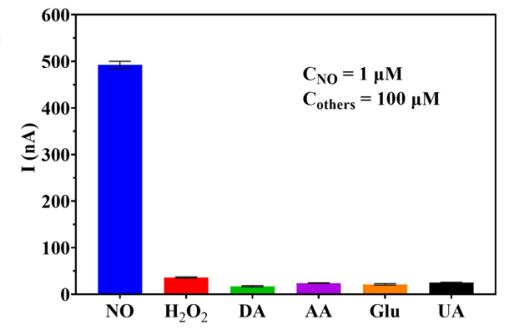

(f)

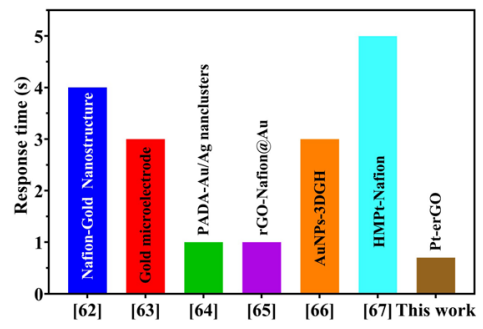

Figure 8. (a) LSV at the Pt-erGO/GCE in $0.1 \mathrm{M}$ PBS ( $\mathrm{pH} 2.5$ ) containing different concentrations of $0.25-400 \mu \mathrm{M}$ of NO, (b) corresponding calibration plot of the anodic peak current response against concentration of NO, (c) chronoamperometeric studies carried out to study the selectivity of the SQ-I electrode toward $\mathrm{NO}$ in the presence of $\mathrm{H}_{2} \mathrm{O}_{2}, \mathrm{DA}, \mathrm{AA}$, Glu, and UA, (d) current responses obtained for $\mathrm{NO}, \mathrm{H}_{2} \mathrm{O}_{2}, \mathrm{DA}$, AA, Glu, and UA at the SQ-I electrode, and (e) response time for $0.25 \mu \mathrm{M}$ of NO at the SQ-I electrode. (f) Comparison of the response time with other literature results.

electroactive species $\left(\mathrm{cm}^{2} \mathrm{~s}^{-1}\right) . D_{\text {app }}$ was calculated to be 3.04 $\times 10^{-6}, 8.84 \times 10^{-4}$, and $7.72 \times 10^{-3} \mathrm{~cm}^{-2} \mathrm{~s}^{-1}$ for bare, SQ-II, and SQ-I electrodes, respectively. This further claims that NO oxidation at the SQ-I electrode is a diffusion-controlled process.

Furthermore, the change in the peak potential $\left(E_{\mathrm{pa}}\right)$ with respect to the logarithm of the scan rate used was studied. It is observed that the peak potentials are said to be increased linearly with respect to the scan rate, indicating the chemically irreversible nature of the electrochemical redox process of NO at the $\mathrm{Pt}-\mathrm{erGO} / \mathrm{GCE}$ surface. From Figure $7 \mathrm{c}$, the linear regression equations between peak potentials $(E)$ and $\log \nu$ are expressed as follows (eq 10).

$$
E_{\mathrm{pa}}=0.108 \times \log \nu+0.831, R^{2}=0.97
$$

$$
\text { (for NO oxidation) }
$$

From the above equation, the electron transfer coefficient was calculated using the Laviron equation eq $11^{75}$

$$
\alpha=\left(\frac{R T}{F}\right) /\left(\frac{\mathrm{d} \ln j_{\mathrm{a}}}{\mathrm{d} E}\right)
$$

where $d \ln j_{a} / d E$ is the slope inverse value obtained from the Tafel plot of $E_{\mathrm{pa}}$ vs $\log (\nu)$ (Figure S6). The calculated electron transfer coefficient $(\alpha)$ is 0.257 . Thus, the above results help in demonstrating the efficient irreversible electron transfer occurring between $\mathrm{Pt}$-erGO and NO, achieved by the enhanced active surface area and higher $D_{\text {app }}$ obtained via electrode modification.

2.2.4. Electrocatalytic Performance of Pt-erGO toward NO. The electrocatalytic performance of $\mathrm{Pt}-\mathrm{erGO}$ in sensing $\mathrm{NO}$ was explored by employing the linear sweep voltammetry technique (LSV). The LSV obtained for different concentrations of NO varying from 0.25 to $400 \mu \mathrm{M}$ is displayed in Figure 8a. A corresponding calibration plot of the concentration of NO versus oxidation current is obtained (Figure 8b) and the linear regression equations (eqs 12-14) for three linear ranges observed are as follows

$$
\begin{aligned}
I= & 0.5745[\mathrm{NO}]+1.06, R^{2}=0.99 \\
& (\text { for } 0.25 \text { to } 40 \mu \mathrm{M}) \\
I= & 0.2746[\mathrm{NO}]+13.68, R^{2}=0.99 \\
& (\text { for } 50 \text { to } 220 \mu \mathrm{M})
\end{aligned}
$$

$$
I=0.1136[\mathrm{NO}]+48.69, R^{2}=0.96
$$

(for 240 to $400 \mu \mathrm{M}$ )

The lowest detection limit (LOD) and the limit of quantification (LOQ) were calculated from LOD $=3 \sigma / \mathrm{m}$ and $\mathrm{LOQ}=10 \sigma / \mathrm{m}$, respectively, where $\sigma$ is the standard deviation of the blank and $m$ is the slope of the calibration curve. The LOD and LOQ values were calculated to be 52, 72, and $232 \mathrm{nM}(\mathrm{S} / \mathrm{N}=3)$ and $0.17,0.24$, and $0.77 \mu \mathrm{M}$ in a linear range of 0.25 to 40,50 to 220 , and 240 to $400 \mu \mathrm{M}$, 

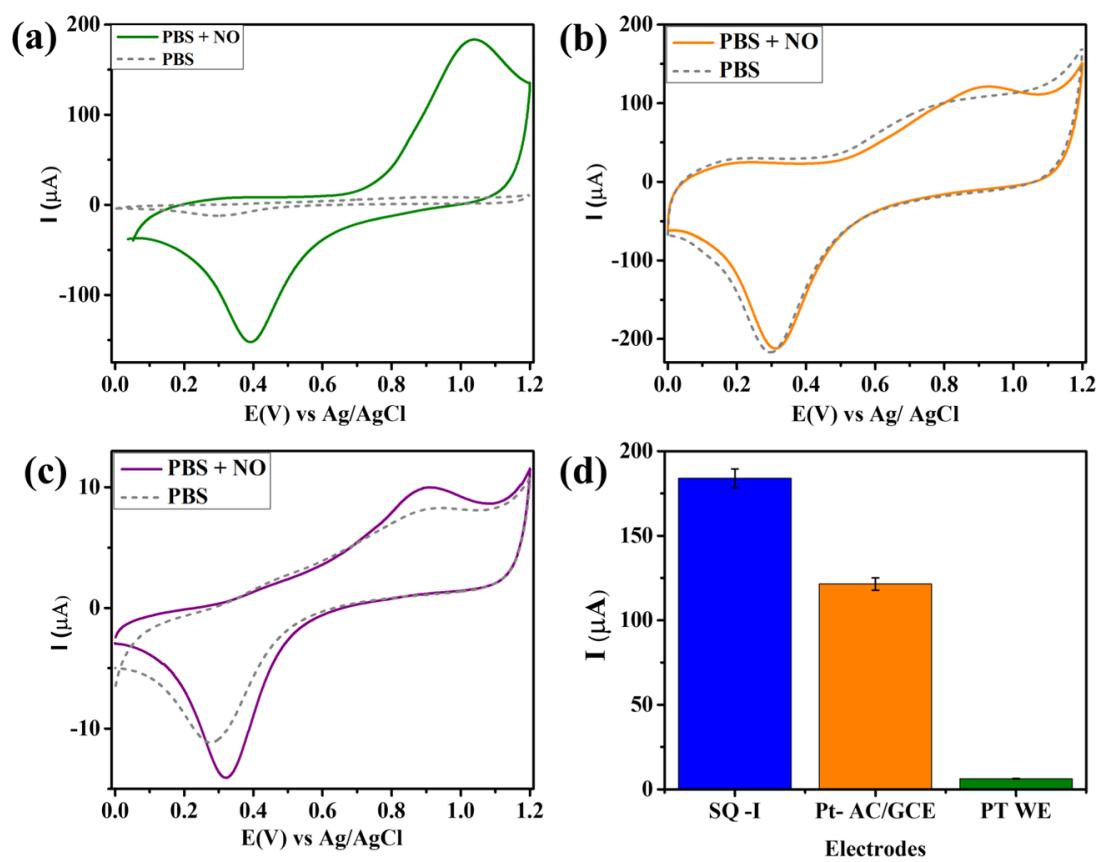

Figure 9. CVs obtained for (a) SQ-I electrode, (b) Pt-AC electrode, and (c) Pt WE in PBS and PBS + 0.5 mM NO. (d) Bar diagram comparing the $I_{\mathrm{pa}}$ values obtained for SQ-I, Pt-AC, and Pt WE.

respectively. The relative standard deviation (RSD) obtained is $5.1 \%$ for NO. Furthermore, the sensitivity was found to be 8.40 $\mu \mathrm{A} \mu \mathrm{M}^{-1} \mathrm{~cm}^{-2}$ for the lowest concentration range ( 0.25 to 40 $\mu \mathrm{M})$.

A comparison of the analytical performance with the previously reported different electrochemical sensors for $\mathrm{NO}$ is listed in the Supporting Information (Table S2). From Table $\mathrm{S} 2$, it is clear that the proposed fabrication method of the PterGO nanocomposite can be used in developing biorecognition probes for detection of $\mathrm{NO}$ at $\mathrm{pH} 2.5$.

2.2.5. Interference Studies. It is of paramount importance to study the influence of interferences by other biomolecules other than NO at the electrode surface for an efficient selective detection of $\mathrm{Pt}-\mathrm{erGO} / \mathrm{GCE}$ on NO. Selectivity of the PterGO/GCE towards $\mathrm{NO}$ was examined by introducing various interfering molecules namely, hydrogen peroxide $\left(\mathrm{H}_{2} \mathrm{O}_{2}\right)$, dopamine (DA), ascorbic acid(AA), glucose(Glu), and uric acid (UA). Figure $8 \mathrm{c}$ depicts the amperometric $i-t$ curve response obtained for the successive addition of $\mathrm{NO}$ and interfering molecules in 0.1 M PBS ( $\mathrm{pH} 2.5$ ) with a time interval of $60 \mathrm{~s}$. Other than for NO addition, no significant current response is noted for interferents. In order to validate the antifouling effect on the Pt-erGO/GCE surface, NO was introduced again to the same system after a series of addition of 100-fold high concentration of various interfering molecules and a significant current response was again observed. Thus, the amperometric response achieved for $\mathrm{Pt}-\mathrm{erGO} / \mathrm{GCE}$ proves that the modified electrode is highly selective towards $\mathrm{NO}$ even in the presence of interfering biomolecules (Figure 8d) and also has a high antifouling surface. This makes the proposed $\mathrm{Pt}-\mathrm{erGO} / \mathrm{GCE}$ a potential biorecognition probe for NO detection. Furthermore, from the $i-t$ curve, the response time of the sensor for $\mathrm{NO}$ detection at $\mathrm{Pt}-\mathrm{erGO} / \mathrm{GCE}$ was determined (Figure 8e). The electrochemical sensor proposed in this work exhibited a fast response time $\Delta t=0.7 \mathrm{~s}$, which is shorter than those reported in several previous studies (Figure 8f).
2.2.6. Reproducibility, Repeatability, and Stability Studies. In order to check the reproducibility, repeatability, and stability of SQ-I (Pt-erGO/GCE), the cyclic voltammetric technique was employed (Figure $\mathrm{S} 7 \mathrm{a}-\mathrm{c}$ ). The reproducibility of $\mathrm{Pt}-$ erGO/GCE was studied for NO detection by recording the $\mathrm{CV}$ of the six different modified electrodes under the same experiment conditions. The electrodes showed only 6.5\% RSD. Furthermore, to evaluate the repeatability performance, a single SQ-I electrode was considered for 50 successive cycles under the same experimental conditions. It was concluded from the study that the electrode could retain $85 \%$ of its initial current response even after 50 cycles. During the period of stability analysis, the $\mathrm{Pt}-\mathrm{erGO} / \mathrm{GCE}$ was stored at room temperature $\left(25^{\circ} \mathrm{C}\right)$ for 15 days. The obtained results ensure that the proposed electrode could retain $83 \%$ of the initial current response.

2.2.7. Comparison of the Proposed Sensor with Pt-AC and Pt WE. The fabricated sensor was compared with $\mathrm{Pt}-$ activated carbon $(\mathrm{Pt}-\mathrm{AC})$ and commercially available $\mathrm{Pt}$ working electrode ( $\mathrm{Pt} \mathrm{WE}$ ) as illustrated in Figure $9 \mathrm{a}-\mathrm{c}$. The fabricated sensor shows a higher current response $(184.53 \mu \mathrm{A})$ for the detection of NO compared to the $\mathrm{Pt}-\mathrm{AC}(120.71 \mu \mathrm{A})$ and Pt WE $(10.04 \mu \mathrm{A})$. In comparison to the commercial Pt $\mathrm{WE}$ and $\mathrm{Pt}-\mathrm{AC}, \mathrm{SQ}-\mathrm{I}$ electrode showed 18.4 and 1.5 times greater current response, respectively (Figure 9d).

2.2.8. Detection of NO in the Human Serum Sample. To investigate the performance of the fabricated sensor, real blood serum sample from a healthy volunteer was tested using the standard addition method. The blood sample was allowed to clot prior to centrifugation at $5000 \mathrm{rpm}$ in order to separate the serum from the blood cells. The linear sweep voltammetric response (to rule out the interference effect) for serum alone and a series of known concentrations of $\mathrm{NO}(25,35$, and 50 $\mu \mathrm{M})$ spiked samples were recorded and given in Figure S8 and Table 1 . The 99.49 to $100.52 \%$ recovery of the analyte clearly suggests the promising sensitivity and accuracy of the proposed 
Table 1. Determination of the NO Level Spiked in Human Blood Serum Using Pt-erGO/GCE

\begin{tabular}{ccccc} 
Sl. no. & spiked $(\mu \mathrm{M})$ & found $(\mu \mathrm{M})$ & recovery $(\%)$ & RSD (\%) \\
\hline 1. & 25 & $26.19 \pm 0.68$ & 101.19 & 3.80 \\
2. & 35 & $35.77 \pm 0.48$ & 99.23 & 4.10 \\
3. & 50 & $49.73 \pm 0.12$ & 99.73 & 2.33 \\
\hline
\end{tabular}

$\mathrm{Pt}$-erGO modified sensor for the determination of $\mathrm{NO}$ in the biological matrix.

\section{CONCLUSIONS}

In summary, the $\mathrm{Pt}$-erGO nanocomposite based electrochemical sensor for NO was successfully developed using the electrochemical method and confirmed using various characterization techniques. The effect of fabrication routes (SQ-I and SQ-II) on the detection of NO was analyzed in depth. The proposed sensor (SQ-I) exhibited $\sim 15$ fold higher current response towards NO in comparison to the bare GCE. This enhancement could be attributed to the higher diffusion coefficient and active surface area obtained for Pt-erGO/GCE than that of the bare GCE. The Pt-erGO/GCE has a LOD = $52 \mathrm{nM}(\mathrm{S} / \mathrm{N}=3)$ and $\mathrm{LOQ}=0.17 \mu \mathrm{M}(\mathrm{S} / \mathrm{N}=10)$ in a linear range of 0.25 to $40 \mu \mathrm{M}$ with a sensitivity of $8.40 \mu \mathrm{A} \mu \mathrm{M}^{-1}$ $\mathrm{cm}^{-2}$. Moreover, the fabricated $\mathrm{Pt}-\mathrm{erGO} / \mathrm{GCE}$ sensor exhibited a low response time of $0.7 \mathrm{~s}$ and good selectivity over $\mathrm{NO}$ in the presence of other interfering biomolecules. Because of the better stability, reproducibility, and practical viability articulated by $\mathrm{Pt}-\mathrm{erGO} / \mathrm{GCE}$, it can be considered as a potential candidate for future clinical applications.

\section{EXPERIMENTAL SECTION}

4.1. Fabrication of Pt@erGO/GCE Electrodes. GO for the studies was prepared using the modified Hummer's oxidation method (Supporting Information-Section II). Prior to modification, the bare GCE was polished successively with 1.0, 0.3, and $0.05 \mu \mathrm{M}$ alumina/water slurries on a polishing pad. Subsequently, the electrode was rinsed with distilled water, and sonicated in ethanol and distilled water for $2 \mathrm{~min}$. In order to study the influence of electrochemical modification of GCE on sensing, SQ-I (Pt-erGO) and SQ-II (erGO-Pt) electrodes were developed, via both sequential methods. ${ }^{61}$

Pt@erGO-modified GCE was developed using two different sequential methods as shown in Scheme 1. In sequential method-I (SQ-I), initially $6 \mu \mathrm{L}$ of $1 \mathrm{mg} / \mathrm{mL} \mathrm{GO}$ in ethanol was dropcasted onto the GCE surface followed by electrochemical reduction of GO to erGO in phosphate buffered saline (PBS, $\mathrm{pH} 7$ ) using the $\mathrm{CV}$ technique in a range of 0 to $-1.2 \mathrm{mV}$ at a scan rate of $50 \mathrm{mV} \mathrm{s}^{-1}$ for 15 successive cycles. ${ }^{22}$ The as obtained erGO-modified GCE was washed and dried at room temperature and its electrode surface was further modified with Pt NPs. For this, erGO/GCE was immersed in a solution of $0.5 \mathrm{mM} \mathrm{H}_{2} \mathrm{PtCl}_{6}$ and $0.1 \mathrm{M} \mathrm{HCl}$ followed by electrochemical deposition of Pt NPs in a potentiodynamic range of -0.4 to $0.5 \mathrm{~V}$ at a scan rate of $50 \mathrm{mV} \mathrm{s}^{-1}$ for 20 successive cycles to obtain $\mathrm{Pt}-\mathrm{erGO} / \mathrm{GCE}$ and the obtained electrode was marked as SQ-I. The sequential method II (SQ-II) was carried out in the reverse way of SQ-I in order to develop the SQ-II electrode. In this method, electrodeposition of Pt NPs on GCE was carried out first and followed by reduction of GO to erGO (erGO-Pt/GCE) under the same experimental conditions as mentioned in developing the SQ-I electrode.

The modified electrodes obtained were washed with distilled water to remove excess unattached Pt NPs from the GCE surface and dried at room temperature to further carry out the experiments. Similarly, Pt/GCE and erGO/GCE electrodes were prepared in single steps via electrodeposition of $\mathrm{Pt}$ and $\mathrm{GO}$ reduction to erGO onto the electrode surface, respectively. GO/GCE was prepared using the simple dropcasting technique in which $6 \mu \mathrm{L}$ of $\mathrm{GO}$ in ethanol $(1 \mathrm{mg} / \mathrm{mL})$ was dropcasted onto the electrode surface and dried at room temperature as followed in the fabrication of both SQ-I and SQ-II methods. All the modified electrodes were washed with distilled water and then used for the electrocatalytic oxidation of nitric oxide (NO).

\section{Scheme 1. Fabrication of SQ-I and SQ-II Electrodes}

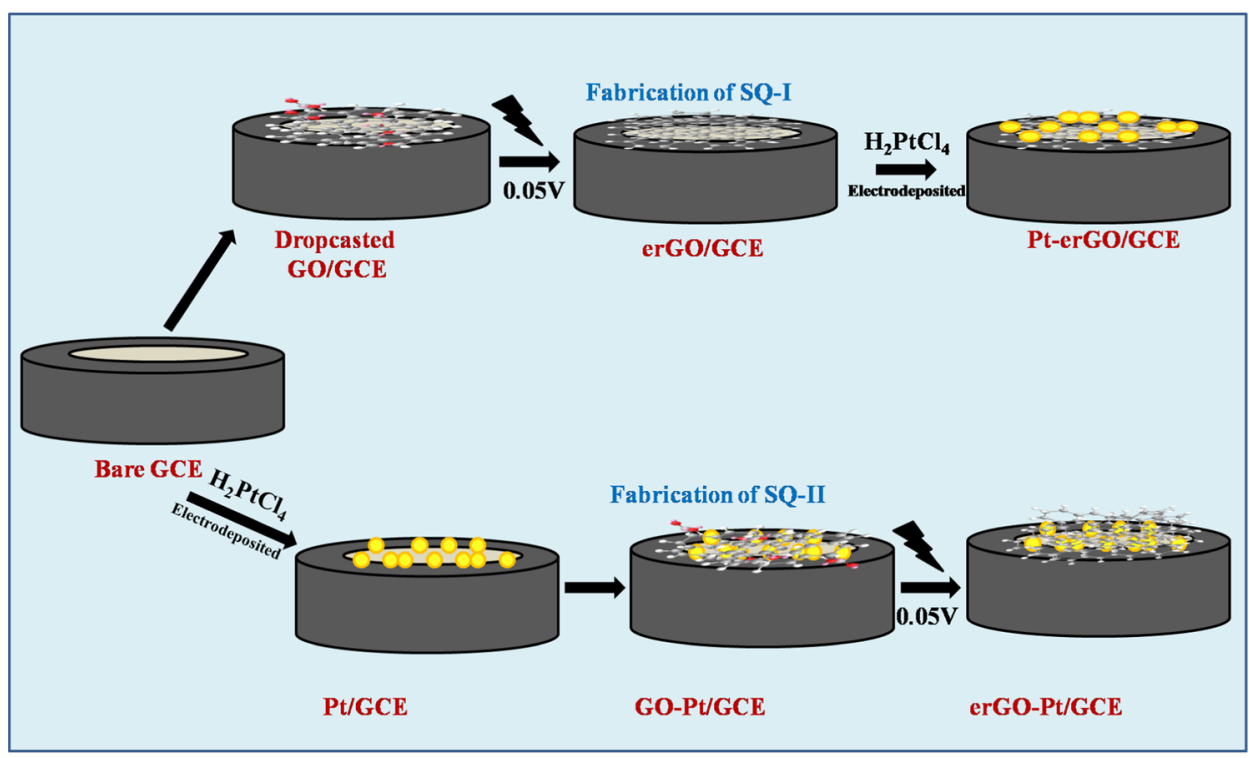




\section{ASSOCIATED CONTENT}

\section{(s) Supporting Information}

The Supporting Information is available free of charge at https://pubs.acs.org/doi/10.1021/acsomega.0c05644.

Reagents and materials; synthesis of graphene oxide (GO); materials characterization; FESEM images obtained for GO; EDS of the Pt-erGO sample; FT-IR spectra obtained for GO, Pt-GO, and Pt-erGO; Tafel plot; real sample analysis; repeatability and stability studies; comparison study of $I_{\mathrm{pa}}, E_{\mathrm{pa}}$ and active surface area of bare and modified electrodes; and comparison study of electrochemical performance of the proposed sensor with others reported in the literature (PDF)

\section{AUTHOR INFORMATION}

\section{Corresponding Author}

Bernaurdshaw Neppolian - SRM Research Institute, SRM Institute of Science and Technology, Chennai, Tamil Nadu 603203, India; (ㅇ) orcid.org/0000-0002-8508-8771; Email: neppolib@srmist.edu.in

\section{Authors}

Georgeena Mathew - SRM Research Institute, SRM Institute of Science and Technology, Chennai, Tamil Nadu 603203, India

Naresh Narayanan - SRM Research Institute, SRM Institute of Science and Technology, Chennai, Tamil Nadu 603203, India

Daniel Arulraj Abraham - National Laboratory of Solid State Microstructures and Department of Materials Science and Engineering, College of Engineering and Applied Sciences, Collaborative Innovation Center of Advanced Microstructures, Nanjing University, Nanjing, Jiangsu 210093, China; 이이.org/0000-0002-3314-6001

Mrinmoy De - Department of Organic Chemistry, Indian Institute of Science, Bangalore, Karnataka 560012, India; (1) orcid.org/0000-0001-8394-9059

Complete contact information is available at: https://pubs.acs.org/10.1021/acsomega.0c05644

\section{Notes}

The authors declare no competing financial interest.

\section{ACKNOWLEDGMENTS}

The authors gratefully acknowledge Department of Science and Technology-Solar Energy Research Initiative (DST-SERI) [File No: DST/SERI/FR/2016/S 170] for their financial support to carry out this research work. The first author would like to thank A. R. M. Shaheer, Aswathy Rajan, and Miriam Daniel, Energy and Environmental Remediation Lab, SRM IST for their valuable contribution.

\section{REFERENCES}

(1) Stratford, M. R. L.; Dennis, M. F.; Cochrane, R.; Parkins, C. S.; Everett, S. A. The Role of Nitric Oxide in Cancer. Improved Methods for Measurement of Nitrite and Nitrate by High-Performance Ion Chromatography. J. Chromatogr. A 1997, 770, 151-155.

(2) Palmer, R. M. J.; Ferrige, A. G.; Moncada, S. Nitric Oxide Release Accounts for the Biological Activity of Endothelium-Derived Relaxing Factor. Nature 1987, 327, 524-526.

(3) Ma, X.; Hu, W.; Guo, C.; Yu, L.; Gao, L.; Xie, J.; Li, C. M. DNATemplated Biomimetic Enzyme Sheets on Carbon Nanotubes to
Sensitively In Situ Detect Superoxide Anions Released from Cells. Adv. Funct. Mater. 2014, 24, 5897-5903.

(4) Lundberg, J. O.; Weitzberg, E.; Gladwin, M. T. The NitrateNitrite-Nitric Oxide Pathway in Physiology and Therapeutics. Nat. Rev. Drug Discovery 2008, 7, 156-167.

(5) Zullino, S.; Buzzella, F.; Simoncini, T. Nitric oxide and the biology of pregnancy. Vasc. Pharmacol. 2018, 110, 71-74.

(6) Yang, L.; Feura, E. S.; Ahonen, M. J. R.; Schoenfisch, M. H. Nitric Oxide-Releasing Macromolecular Scaffolds for Antibacterial Applications. Adv. Healthcare Mater. 2018, 7, 1800155.

(7) Vahora, H.; Khan, M. A.; Alalami, U.; Hussain, A. The Potential Role of Nitric Oxide in Halting Cancer Progression Through Chemoprevention. Int. J. Canc. Prev. 2016, 21, 1-12.

(8) Kelm, M. Nitric oxide metabolism and breakdown. Biochim. Biophys. Acta 1999, 1411, 273-289.

(9) Heales, S. J. R.; Bolaños, J. P.; Stewart, V. C.; Brookes, P. S.; Land, J. M.; Clark, J. B. Nitric Oxide, Mitochondria and NNeurological Disease. Biochim. Biophys. Acta Bioenerg. 1999, 1410, 215-228.

(10) Pluth, M. D.; Tomat, E.; Lippard, S. J. Bio Chemistry of Mobile Zinc and Nitric Oxide Revealed by Fluorescent Sensors. Annu. Rev. Biochem. 2011, 80, 333.

(11) Choudhari, S. K.; Chaudhary, M.; Bagde, S.; Gadbail, A. R.; Joshi, V. Nitric Oxide and Cancer:A Review. World J. Surg. Oncol. 2013, 11, 118.

(12) Beckman, J. S.; Koppenol, W. H. Nitric Oxide, Superoxide, and Peroxynitrite: the Good, the Bad, and the Ugly. Am. J. Physiol. Cell Physiol. 1996, 271, C1424-C1437.

(13) Tonzetich, Z. J.; McQuade, L. E.; Lippard, S. J. Detecting and Understanding the Roles of Nitric Oxide in Biology. Inorg. Chem. 2010, 49, 6338-6348.

(14) Gomes, F. O.; Maia, L. B.; Loureiro, J. A.; Pereira, M. C.; Delerue-Matos, C.; Moura, I.; Moura, J. J. G.; Morais, S. Biosensor for direct bioelectrocatalysis detection of nitric oxide using nitric oxide reductase incorporated in carboxylated single-walled carbon nanotubes/lipidic 3 bilayer nanocomposite. Bioelectrochemistry 2019, 127, 76-86.

(15) Pandikumar, A.; Soon How, G. T.; See, T. P.; Omar, F. S.; Jayabal, S.; Kamali, K. Z.; Yusoff, N.; Jamil, A.; Ramaraj, R.; John, S. A.; Lim, H. N.; Huang, N. M. Graphene and its Nanocomposite Material based Electrochemical Sensor platform for dopamine. RSC Adv. 2014, 4, 63296-63323.

(16) Wang, H.; Li, H.; Huang, Y.; Xiong, M.; Wang, F.; Li, C. A label-free electrochemical biosensor for highly sensitive detection of gliotoxin based on DNA nanostructure/MXene nanocomplexes. Biosens. Bioelectron. 2019, 142, 111531.

(17) Zhang, X.; Xie, G.; Gou, D.; Luo, P.; Yao, Y.; Chen, H. A novel enzyme-free electrochemical biosensor for rapid detection of Pseudomonas aeruginosa based on high catalytic Cu-ZrMOF and conductive Super P. Biosens. Bioelectron. 2019, 142, 111486.

(18) Rashidi, K.; Mahmoudi, M.; Mohammadi, G.; Zangeneh, M. M.; Korani, S.; Goicoechea, H. C.; Gu, H.-W.; Jalalvand, A. R. Simultaneous co-immobilization of three enzymes onto a modified glassy carbon electrode to fabricate a high-performance amperometric biosensor for determination of total cholesterol. Int. J. Biol. Macromol. 2018, 120, 587-595.

(19) Ibáñez-Redín, G.; Silva, T. A.; Vicentini, F. C.; Fatibello-Filho, O. Effect of carbon black functionalization on the analytical performance of a tyrosinase biosensor based on glassy carbon electrode modified with dihexadecylphosphate film. Enzym. Microb. Technol. 2018, 116, 41-47.

(20) Cunci, L.; Velez, C. A.; Perez, I.; Suleiman, A.; Larios, E.; JoséYacamán, M.; Watkins, J. J.; Watkins, J. J.; Cabrera, C. R. Platinum electrodeposition at unsupported electrochemically reduced nanographene oxide for enhanced ammonia oxidation. ACS Appl. Mater. Interfaces 2014, 6, 2137-2145.

(21) Oh, J.; Lee, J. S.; Jun, J.; Kim, S. G.; Jang, J. Ultrasensitive and Selective Organic FET-type Nonenzymatic Dopamine Sensor Based 
on Platinum Nanoparticles-Decorated Reduced Graphene Oxide. ACS Appl. Mater. Interfaces 2017, 9, 39526-39533.

(22) Mathew, G.; Dey, P.; Das, R.; Chowdhury, S. D.; Paul Das, M.; Veluswamy, P.; Neppolian, B.; Das, J. Direct electrochemical reduction of hematite decorated graphene oxide $\left(\alpha-\mathrm{Fe}_{2} \mathrm{O}_{3} @ e r G O\right)$ nanocomposite for selective detection of Parkinson's disease biomarker. Biosens. Bioelectron. 2018, 115, 53-60.

(23) Zhang, T.; Wei, J.-Z.; Sun, X.-J.; Zhao, X.-J.; Tang, H.-l.; Yan, H.; Zhang, F.-M. Continuous and Rapid Synthesis of UiO-67 by Electrochemical Methods for the Electrochemical Detection of Hydroquinone. Inorg. Chem. 2020, 59, 8827-8835.

(24) Liu, Y.; Shi, W.-J.; Lu, Y.-K.; Liu, G.; Hou, L.; Wang, Y.-Y. Nonenzymatic Glucose Sensing and Magnetic Property Based On the Composite Formed by Encapsulating Ag Nanoparticles in ClusterBased Co-MOF. Inorg. Chem. 2019, 58, 16743-16751.

(25) Wu, F.-H.; Zhao, G.-C.; Wei, X.-W. Electrocatalytic oxidation of nitric oxide at multi-walled carbon nanotubes modified electrode. Electrochem. Commun. 2002, 4, 690-694.

(26) He, Q.; Zheng, D.; Hu, S. Development and application of a nano-alumina based nitric oxide sensor. Microchim. Acta 2009, 164, 459-464.

(27) Thangavel, S.; Ramaraj, R. Polymer Membrane Stabilized Gold Nanostructures Modified Electrode and Its Application in Nitric Oxide Detection. J. Phys. Chem. C 2008, 112, 19825-19830.

(28) Shahid, M. M.; Rameshkumar, P.; Pandikumar, A.; Lim, H. N.; $\mathrm{Ng}$, Y. H.; Huang, N. M. An electrochemical sensing platform based on a reduced graphene oxide-cobalt oxide nanocube@platinum nanocomposite for nitric oxide detection. J. Mater. Chem. A 2015, 3, $14458-14468$.

(29) Geetha Bai, R.; Muthoosamy, K.; Zhou, M.; Ashokkumar, M.; Huang, N. M.; Manickam, S. Sonochemical and sustainable Synthesis of Graphene-Gold (G-Au) nanocomposites for enzymeless and selective electrochemical detection of nitric oxide. Biosens. Bioelectron. 2017, 87, 622-629.

(30) Brown, M. D.; Schoenfisch, M. H. Selective and sensocompatible electrochemical nitric oxide sensor with a bilaminar design. ACS Sens. 2019, 4, 1766-1773.

(31) Chandran, B.; Janakiraman, K. New Disposable Nitric Oxide Sensor Fabrication Using GaN Nanowires. ACS Omega 2019, 4, 17171-17176.

(32) Gill, A.; Zajda, J.; Meyerhoff, M. E. Comparison of electrochemical nitric oxide detection methods with chemiluminescence for measuring nitrite concentration in food samples. Anal. Chim. Acta 2019, 1077, 167-173.

(33) Zhang, Y.; Guo, C. X.; Wu, C.; Du, H.; Chen, Q.; Gao, J.-C.; Shi, Z.; Tang, K.-L.; Li, C. M. Electrochemically tuning $\mathrm{Li}_{1+\mathrm{x}} \mathrm{FePO}_{4}$ for high oxidation state of rich $\mathrm{Li}^{+}$toward highly sensitive detection of nitric oxide. Electrochim. Acta 2021, 365, 137347.

(34) Deng, X.; Zou, Z.; Zhang, Y.; Gao, J.; Liang, T.; Lu, Z.; Ming $\mathrm{Li}, \mathrm{C}$. Synthesis of merit-combined antimony tetroxide nanoflowers/ reduced graphene oxide to synergistically boost real-time detection of nitric oxide released from living cells for high sensitivity. J. Colloid Interface Sci. 2021, 581, 465-474.

(35) Li, R.; Qi, H.; Ma, Y.; Deng, Y.; Liu, S.; Jie, Y.; Jing, J.; He, J.; Zhang, X.; Wheatley, L.; Huang, C.; Sheng, X.; Zhang, M.; Yin, L. A flexible and physically transient electrochemical sensor for real-time wireless nitric oxide monitoring. Nat. Commun. 2020, 11, 3207.

(36) Zhou, M.; Jiang, Y.; Wang, G.; Wu, W.; Chen, W.; Yu, P.; Lin, Y.; Mao, J.; Mao, L. Single-atom Ni-N4 provides a robust cellular NO sensor. Nat. Commun. 2020, 11, 3188.

(37) Meiller, A.; Sequeira, E.; Marinesco, S. Electrochemical Nitric Oxide Microsensors Based on a Fluorinated Xerogel Screening Layer for in Vivo Brain Monitoring. Anal. Chem. 2020, 92, 1804-1810.

(38) DIaconu, R.; Dumitrescu, F.; Stoica, L.; Ciobanu, O. M.; Udristoiu, I.; Stan, I. V.; Selaru, L. Electrochemical detection of the exhaled nitric oxide in children. Rev. Chem. 2020, 71, 105-109.

(39) Zhu, P.; Li, S.; Zhou, S.; Ren, N.; Ge, S.; Zhang, Y.; Wang, Y.; $\mathrm{Yu}, \mathrm{J}$. In situ grown COFs on $3 \mathrm{D}$ strutted graphene aerogel for electrochemical detection of NO released from living cells. Chem. Eng. J. 2020, 127559.

(40) Hafeez, H. Y.; Lakhera, S. K.; Bellamkonda, S.; Rao, G. R.; Shankar, M. V.; Bahnemann, D. W.; Neppolian, B. Construction of ternary hybrid layered reduced graphene oxide supported $\mathrm{g}_{-} \mathrm{C}_{3} \mathrm{~N} 4$ $\mathrm{TiO}_{2}$ nanocomposite and its photocatalytic hydrogen production activity. Int. J. Hydrogen Energy 2018, 43, 3892-3904.

(41) Chou, S. S.; De, M.; Luo, J.; Rotello, V. M.; Huang, J.; Dravid, V. P. Nanoscale graphene oxide (nGO) as artificial receptors: implications for biomolecular interactions and sensing. J. Am. Chem. Soc. 2012, 134, 16725-16733.

(42) Babu, S. G.; Karthik, P.; John, M. C.; Lakhera, S. K.; Ashokkumar, M.; Khim, J.; Neppolian, B. Synergistic effect of sonophotocatalytic process for the degradation of organic pollutants using $\mathrm{CuO}-\mathrm{TiO}_{2}$ /rGO. Ultrason. Sonochem. 2019, 50, 218-223.

(43) Abdolhosseinzadeh, S.; Sadighikia, S.; Alkan Gürsel, S. Scalable Synthesis of Sub-Nanosized Platinum-Reduced Graphene Oxide Composite by an Ultraprecise Photocatalytic Method. ACS Sustain. Chem. Eng. 2018, 6, 3773-3782.

(44) Li, D.; Wang, T.; Li, Z.; Xu, X.; Wang, C.; Duan, Y. Application of graphene-based materials for detection of nitrate and nitrite in water-a review. Sensors 2019, 20, 54.

(45) Li, G.; Xia, Y.; Tian, Y.; Wu, Y.; Liu, J.; He, Q.; Chen, D. Review-Recent developments on graphene-based electrochemical sensors toward nitrite. J. Electrochem. Soc. 2019, 166, B881.

(46) Shim, K.; Kim, J.; Shahabuddin, M.; Yamauchi, Y.; Hossain, M. S. A.; Kim, J. H. Efficient wide range electrochemical bisphenol-A sensor by self-supported dendritic platinum nanoparticles on screenprinted carbon electrode. Sens. Actuators, B 2018, 255, 2800-2808.

(47) Naresh, N.; Karthik, P.; Vinoth, R.; Muthamizhchelvan, C.; Neppolian, B. Tailoring multi-metallic nanotubes by copper nanowires with platinum and gold via galvanic replacement route for the efficient methanol oxidation reaction. Electrochim. Acta 2018, 282, 792-798.

(48) Bach, L. G.; Thi, M. L. N.; Son, N. T.; Bui, Q. B.; Nhac-Vu, H.T.; Ai-Le, P. H. Mesoporous gold nanoparticles supported cobalt nanorods as a free-standing electrochemical sensor for sensitive hydrogen peroxide detection. J. Electroanal. Chem. 2019, 848, 113359. DOI: $10.1016 /$ j.jelechem.2019.113359

(49) Javan, H.; Asghari, E.; Ashassi-Sorkhabi, H. Fabrication and electrochemical kinetics studies of reduced carbon quantum dotssupported palladium nanoparticles as bifunctional catalysts in methanol oxidation and hydrogen evolution reactions. Synth. Met. 2019, 254, 153-163.

(50) Kumar, M. A.; Lakshminarayanan, V.; Ramamurthy, S. S. Platinum nanoparticles-decorated graphene-modified glassy carbon electrode toward the electrochemical determination of ascorbic acid, dopamine, and paracetamol. C. R. Chim. 2019, 22, 58-72.

(51) Parate, K.; Karunakaran, C.; Claussen, J. C. Electrochemical cotinine sensing with a molecularly imprinted polymer on a grapheneplatinum nanoparticle modified carbon electrode towards cigarette smoke exposure monitoring. Sens. Actuators, B 2019, 287, 165-172. (52) Vinodgopal, K.; Neppolian, B.; Salleh, N.; Lightcap, I. V.; Grieser, F.; Ashokkumar, M.; Ding, T. T.; Kamat, P. V. Dualfrequency ultrasound for designing two dimensional catalyst surface: Reduced graphene oxide-Pt composite. Colloids Surf., A 2012, 409, 81-87.

(53) Sha, R.; Badhulika, S. Facile synthesis of three-dimensional platinum nanoflowers decorated reduced graphene oxide: An ultrahigh performance electro-catalyst for direct methanol fuel cells. Mater. Sci. Eng., B 2018, 231, 115-120.

(54) Chen, D.-J.; Zhang, Q.-L.; Feng, J.-X.; Ju, K.-J.; Wang, A.-J.; Wei, J.; Feng, J.-J. One-pot wet-chemical co-reduction synthesis of bimetallic gold-platinum nanochains supported on reduced graphene oxide with enhanced electrocatalytic activity. J. Power Sources 2015, 287, 363-369.

(55) Ghasemi, S.; Hosseini, S. R.; Moalem-Banhangi, M. Preparation of electrochemically reduced graphene oxide/bimetallic copper- 
platinum nanohybrid as counter electrode for fabrication of dyesensitized solar cell. J. Electroanal. Chem. 2019, 833, 242-250.

(56) Privett, B. J.; Shin, J. H.; Schoenfisch, M. H. Electrochemical nitric oxide sensors for physiological measurements. Chem. Soc. Rev. 2010, 39, 1925-1935.

(57) Kalambate, P. K.; Sanghavi, B. J.; Karna, S. P.; Srivastava, A. K. Simultaneous voltammetric determination of paracetamol and domperidone based on a graphene/platinum nanoparticles/nafion composite modified glassy carbon electrode. Sens. Actuators, B 2015, 213, 285-294.

(58) El-Hallag, I. S.; El-Nahass, M. N.; Youssry, S. M.; Kumar, R.; Abdel-Galeil, M. M.; Matsuda, A. Facile in-situ simultaneous electrochemical reduction and deposition of reduced graphene oxide embedded palladium nanoparticles as high performance electrode materials for supercapacitor with excellent rate capability. Electrochim. Acta 2019, 314, 124-134.

(59) Zhou, Y.-G.; Chen, J.-J.; Wang, F.-b.; Sheng, Z.-H.; Xia, X.-H. A facile approach to the synthesis of highly electroactive Ptnanoparticles on graphene as an anode catalyst for direct methanolfuelcells. Chem. Commun. 2010, 46, 5951-5953.

(60) Deng, S.; Berry, V. Wrinkled, rippled and crumpled graphene: an overview of formation mechanism, electronic properties, and applications. Mater. Today 2016, 19, 197-212.

(61) Li, M.; Bo, X.; Mu, Z.; Zhang, Y.; Guo, L. Electrodeposition of nickel oxide and platinum nanoparticles on electrochemically reduced graphene oxide film as a nonenzymatic glucose sensor. Sens. Actuators, B 2014, 192, 261-268.

(62) Chen, Y.; Niu, Y.; Tian, T.; Zhang, J.; Wang, Y.; Li, Y.; Qin, L.C. Microbial reduction of graphene oxide by Azotobacter chroococcum. Chem. Phys. Lett. 2017, 677, 143-147.

(63) Burhan, H.; Ay, H.; Kuyuldar, E.; Sen, F. Monodisperse Pt-Co/ GO anodes with varying Pt: Co ratios as highly active and stable electrocatalysts for methanol electrooxidation reaction. Sci. Rep. 2020, $10,6114$.

(64) Huang, Y.-T.; Lee, H.; Li, W.-D.; Feng, S.-P. Engineered platinum nanoparticles via pulse electrochemical deposition for bifacially transparent and efficient full-plastic dye-sensitized solar cells. J. Power Sources 2019, 435, 226801.

(65) Zhou, Z.; Yuan, S.; Fan, J.; Hou, Z.; Zhou, W.; Du, Z.; Wu, S. $\mathrm{CuInS}_{2}$ quantum dot-sensitized $\mathrm{TiO} 2$ nanorod array photoelectrodes: synthesis and performance optimization. Nanoscale Res. Lett. 2012, 7, 652.

(66) Narayanan, N.; Bernaurdshaw, N. Reduced Graphene Oxide Supported NiCo2O4 Nano-Rods: An Efficient, Stable and CostEffective Electrocatalyst for Methanol Oxidation Reaction. ChemCatChem 2019, 12, 771-780.

(67) Olejnik, P.; Świetlikowska, A.; Gniadek, M.; Pałys, B. Electrochemically Reduced Graphene Oxide on Electrochemically Roughened Gold as a Support for Horseradish Peroxidase. J. Phys. Chem. C 2014, 118, 29731-29738.

(68) Bhardwaj, S. K.; Yadav, P.; Ghosh, S.; Basu, T.; Mahapatro, A. K. Biosensing Test-Bed Using Electrochemically Deposited Reduced Graphene Oxide. ACS Appl. Mater. Interfaces 2016, 8, 24350-24360.

(69) Yu, X.; Zhang, M.; Yuan, W.; Shi, G. High-performance threedimensional Ni-Fe layered double hydroxide/graphene electrode for water oxidation. J. Mater. Chem. A 2015, 3, 6921-6928.

(70) Kim, J.; Jung, S.; Kim, H.-J.; Kim, Y.; Lee, C.; Kim, S. M.; Kim, D.; Jun, Y. SiNW/C@Pt Arrays for High-Efficiency Counter Electrodes in Dye-Sensitized Solar Cells. Energies 2019, 13, 139.

(71) Dao, V.-D.; Hoa, N. T. Q.; Larina, L. L.; Lee, J.-K.; Choi, H.-S. Graphene-Platinum Nanohybrid as a Robust and Low-cost Counter Electrode for Dye-sensitized Solar Cells. Nanoscale 2013, 5, 1223712244.

(72) de Vooys, A. C. A.; Beltramo, G. L.; van Riet, B.; van Veen, J. A. R.; Koper, M. T. M. Mechanisms of electrochemical reduction and oxidation of nitric oxide. Electrochim. Acta 2004, 49, 1307-1314.

(73) Wang, Z.; Ai, F.; Xu, Q.; Yang, Q.; Yu, J.-H.; Huang, W.-H.; Zhao, Y.-D. Electrocatalytic activity of salicylic acid on the platinum nanoparticles modified electrode by electrochemical deposition. Colloids Surf., B 2010, 76, 370-374.

(74) Bagheri, H.; Afkhami, A.; Hashemi, P.; Ghanei, M. Simultaneous and sensitive determination of melatonin and dopamine with $\mathrm{Fe}_{3} \mathrm{O}_{4}$ nanoparticle-decorated reduced graphene oxide modified electrode. RSC Adv. 2015, 5, 21659-21669.

(75) Singh, M.; Bhardiya, S. R.; Kashyap, H.; Verma, F.; Rai, V. K.; Tiwari, I. Decoration of GO with Fe spinel-Naf/DMAP: an electrochemical probe for sensing $\mathrm{H}_{2} \mathrm{O}_{2}$ reduction. RSC Adv. 2016, 6, 104868-104874. 